\title{
Satellite observations of atmospheric methane and their value for quantifying methane emissions
}

\author{
Daniel J. Jacob ${ }^{1}$, Alexander J. Turner ${ }^{1}$, Joannes D. Maasakkers ${ }^{1}$, Jianxiong Sheng ${ }^{1}$, Kang Sun ${ }^{2}$, Xiong Liu ${ }^{2}$, \\ Kelly Chance $^{2}$, Ilse Aben ${ }^{3}$, Jason McKeever ${ }^{4}$, and Christian Frankenberg ${ }^{5}$ \\ ${ }^{1}$ School of Engineering and Applied Sciences, Harvard University, Cambridge, MA 02138, USA \\ ${ }^{2}$ Smithsonian Astrophysical Observatory, Cambridge, MA 02138, USA \\ ${ }^{3}$ SRON Netherlands Institute for Space Research, Utrecht, 3584, the Netherlands \\ ${ }^{4}$ GHGSat, Inc., Montreal, H2W 1Y5, Canada \\ ${ }^{5}$ California Institute of Technology, Pasadena, CA 91125, USA \\ Correspondence to: Daniel J. Jacob (djacob@fas.harvard.edu)
}

Received: 24 June 2016 - Published in Atmos. Chem. Phys. Discuss.: 28 June 2016

Revised: 31 October 2016 - Accepted: 31 October 2016 - Published: 18 November 2016

\begin{abstract}
Methane is a greenhouse gas emitted by a range of natural and anthropogenic sources. Atmospheric methane has been measured continuously from space since 2003, and new instruments are planned for launch in the near future that will greatly expand the capabilities of space-based observations. We review the value of current, future, and proposed satellite observations to better quantify and understand methane emissions through inverse analyses, from the global scale down to the scale of point sources and in combination with suborbital (surface and aircraft) data. Current global observations from Greenhouse Gases Observing Satellite (GOSAT) are of high quality but have sparse spatial coverage. They can quantify methane emissions on a regional scale $(100-1000 \mathrm{~km})$ through multiyear averaging. The Tropospheric Monitoring Instrument (TROPOMI), to be launched in 2017, is expected to quantify daily emissions on the regional scale and will also effectively detect large point sources. A different observing strategy by GHGSat (launched in June 2016) is to target limited viewing domains with very fine pixel resolution in order to detect a wide range of methane point sources. Geostationary observation of methane, still in the proposal stage, will have the unique capability of mapping source regions with high resolution, detecting transient "super-emitter" point sources and resolving diurnal variation of emissions from sources such as wetlands and manure. Exploiting these rapidly expanding satellite measurement capabilities to quantify methane emissions requires a parallel effort to construct high-quality spa-
\end{abstract}

tially and sectorally resolved emission inventories. Partnership between top-down inverse analyses of atmospheric data and bottom-up construction of emission inventories is crucial to better understanding methane emission processes and subsequently informing climate policy.

\section{Introduction}

Methane is a greenhouse gas emitted by anthropogenic sources including livestock, oil-gas systems, landfills, coal mines, wastewater management, and rice cultivation. Wetlands are the dominant natural source. The atmospheric concentration of methane has risen from 720 to $1800 \mathrm{ppb}$ since preindustrial times (Hartmann et al., 2013). The resulting radiative forcing on an emission basis is $0.97 \mathrm{~W} \mathrm{~m}^{-2}$, compared to $1.68 \mathrm{~W} \mathrm{~m}^{-2}$ for $\mathrm{CO}_{2}$ (Myhre et al., 2013). The present-day global emission of methane is well known to be $550 \pm 60 \mathrm{Tg} \mathrm{a}^{-1}$, as inferred from mass balance with the global methane sink from oxidation by $\mathrm{OH}$ radicals (Prather et al., 2012). However, the contributions from different source sectors and source regions are highly uncertain (Dlugokencky et al., 2011; Kirschke et al., 2013). Emission inventories used for climate policy rely on "bottom-up" estimates of activity rates and emission factors for individual source processes. "Top-down" information from observations of atmospheric methane is often at odds with these estimates and differences need to be reconciled (Brandt et 


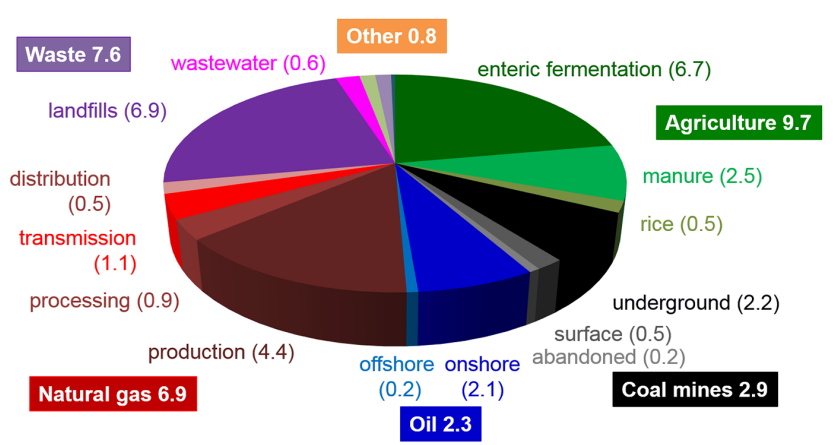

Figure 1. US national anthropogenic emission inventory for methane in 2012 compiled by the US EPA (2016). Units are Tg $\mathrm{a}^{-1}$. "Other" sources include mainly fuel combustion $\left(0.4 \mathrm{Tg} \mathrm{a}^{-1}\right)$ and open fires $\left(0.4 \mathrm{Tg} \mathrm{a}^{-1}\right)$.

al., 2014). Satellite observations of atmospheric composition have emerged over the past decade as a promising resource to infer emissions of various gases (Streets et al., 2013). Here we review present, near-future, and proposed satellite observations of atmospheric methane and assess their value for quantifying emissions, from regional scales down to the scale of individual point sources.

The United Nations Framework Convention on Climate Change (UNFCCC) requires individual countries to report their annual anthropogenic greenhouse gas emissions following bottom-up inventory guidelines from the International Panel on Climate Change (IPCC, 2006). As an example, Fig. 1 shows the US anthropogenic methane emission inventory for 2012 compiled by the Environmental Protection Agency (US EPA, 2016) and reported to the UNFCCC. The inventory uses advanced IPCC Tier 2/3 methods (IPCC, 2006) with detailed sectoral information. However, atmospheric observations from surface sites and aircraft suggest that US emissions are underestimated, and that sources from natural gas and livestock are likely responsible (Miller et al., 2013; Brandt et al., 2014). Not included in Fig. 1 are wetland emissions, estimated to be $8.5 \pm 5.5 \mathrm{Tg} \mathrm{a}^{-1}$ for the contiguous US (Melton et al., 2013). The global distribution of wetland emissions is extremely uncertain (Bloom et al., 2016) and quantifying these emissions through atmospheric observations is of critical importance.

Targeted atmospheric measurements of methane can quantify emissions on small scales (point source, urban area, oilgas basin) by measuring the ratio of methane to a co-emitted species whose emission is known (Wennberg et al., 2012) or by using a simple mass balance approach (Karion et al., 2013; Peischl et al., 2016; Conley et al., 2016). Quantifying emissions on larger scales, with many contributing sources, requires a more general approach where an ensemble of atmospheric observations is fit to a 2-D field of emissions by inversion of a 3-D chemical transport model (CTM) that relates emissions to atmospheric concentrations. This inversion is usually done by Bayesian optimization accounting for er- rors in the CTM, in the observations, and in the prior knowledge expressed by the bottom-up inventory. We obtain from the inversion a statistically optimized emission field, and differences with the bottom-up inventory point to areas where better understanding of processes is needed. A large number of inverse studies have used surface and aircraft observations to quantify methane emissions on regional to global scales (Bergamaschi et al., 2005; Bousquet et al., 2011; Miller et al., 2013; Bruhwiler et al., 2014).

Satellites provide global and dense data that are particularly well suited for inverse analyses. Measurement of methane from space began with the IMG thermal infrared instrument in 1996-1997 (Clerbaux et al., 2003). Measurement of total methane columns by solar backscatter began with SCIAMACHY in 2003-2012 (Frankenberg et al., 2006) and continues to the present with Greenhouse Gases Observing Satellite (GOSAT) launched in 2009 (Kuze et al., 2016). Satellite measurements of atmospheric methane have been used to detect emission hotspots (Worden et al., 2012; Kort et al., 2014; Marais et al., 2014; Buchwitz et al., 2016) and to estimate emission trends (Schneising et al., 2014; Turner et al., 2016). They have been used in global inverse analyses to estimate emissions on regional scales (Bergamaschi et al., 2007, 2009, 2013; Monteil et al., 2013; Cressot et al., 2014; Wecht et al., 2014a; Alexe et al., 2015; Turner et al., 2015). The TROPOMI instrument scheduled for launch in 2017 will vastly expand the capability to observe methane from space by providing complete daily global coverage with $7 \times 7 \mathrm{~km}^{2}$ resolution (Veefkind et al., 2012; Butz et al., 2012). The GHGSat instrument launched on a microsatellite in June 2016 by the Canadian company GHGSat, Inc. has $50 \times 50 \mathrm{~m}^{2}$ pixel resolution over targeted viewing domains for detection of point sources. GOSAT-2, a successor of GOSAT featuring higher precision, is scheduled for launch in 2018. The MERLIN lidar instrument (Kiemle et al., 2011,2014 ) is scheduled for launch in 2020. Additional instruments are currently being planned or proposed. As the demand for global monitoring of methane emissions grows, it is timely to review the capabilities and limitations of present and future satellite observations.

\section{Observing methane from space}

\subsection{Instruments and retrievals}

Table 1 lists the principal instruments (past, current, planned, proposed) measuring methane from space. Atmospheric methane is detectable by its absorption of radiation in the shortwave infrared (SWIR) at 1.65 and $2.3 \mu \mathrm{m}$, and in the thermal infrared (TIR) around $8 \mu \mathrm{m}$. Figure 2 shows different satellite instrument configurations. SWIR instruments measure solar radiation backscattered by the Earth and its atmosphere. The MERLIN lidar instrument will emit its own SWIR radiation and detect methane in the backscattered laser 


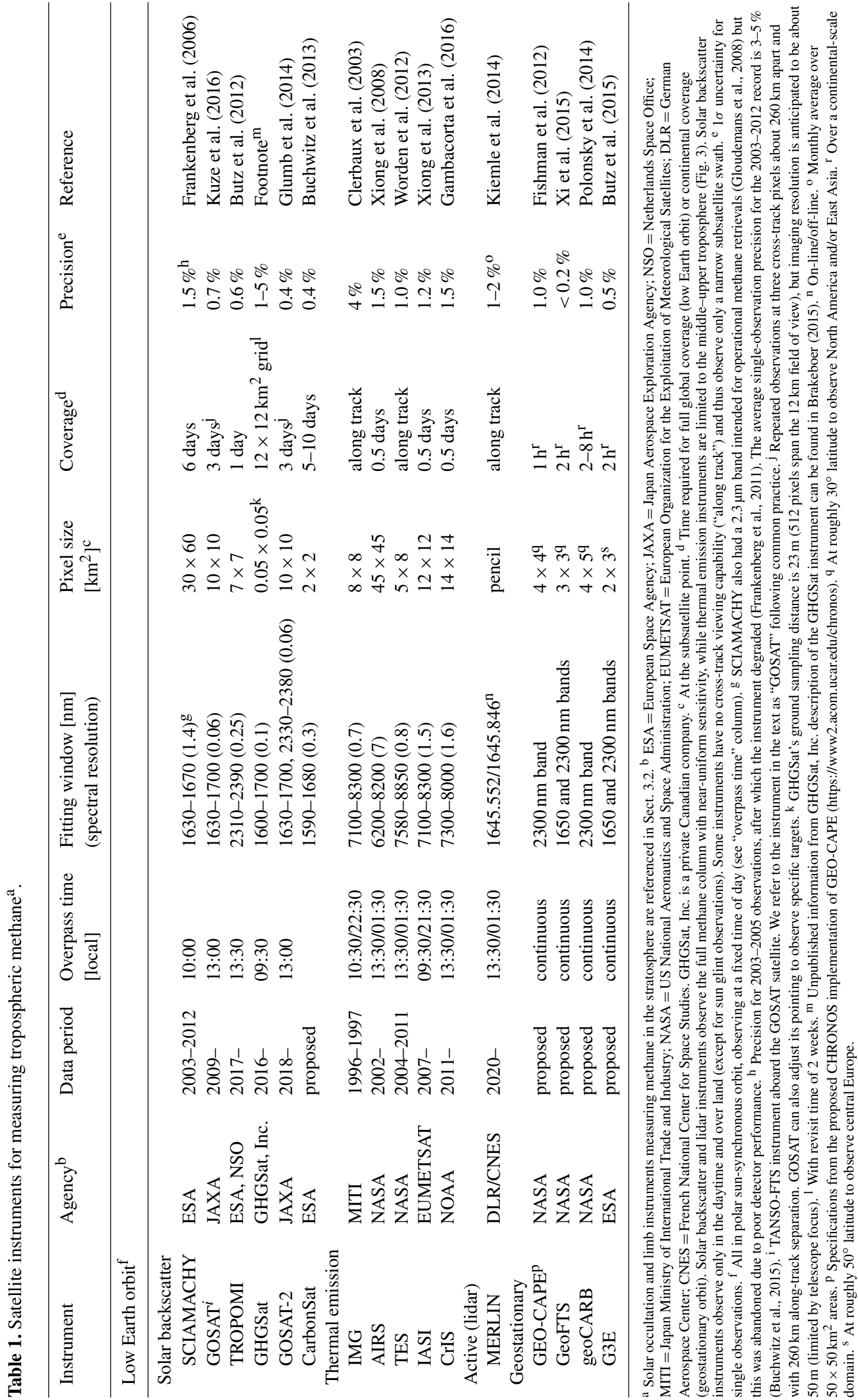




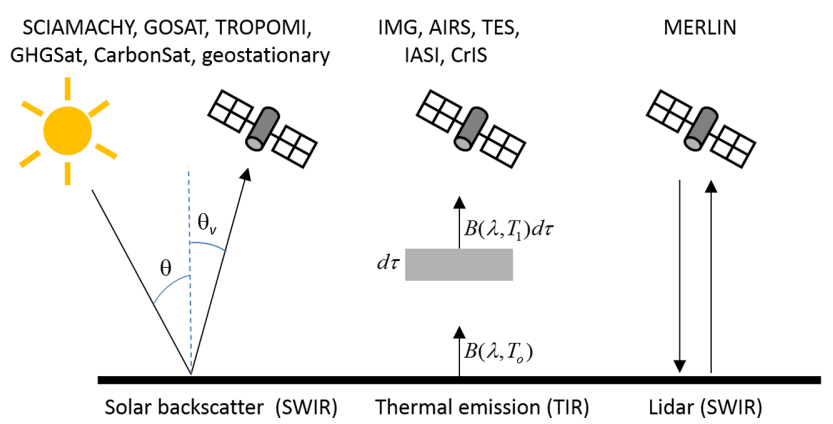

Figure 2. Configurations for observing methane from space in the shortwave infrared (SWIR) and in the thermal infrared (TIR). Here $\theta$ is the solar zenith angle, $\theta_{\mathrm{v}}$ is the satellite viewing angle, $B(\lambda, T)$ is the blackbody function of wavelength $\lambda$ and temperature $T$ ( $T_{o}$ at the surface, $T_{1}$ at the altitude of the emitting methane), and $d \tau$ is the elemental methane optical depth. Satellite instruments operating in the different configurations are identified in the Figure and listed in Table 1.

signal. TIR instruments measure blackbody terrestrial radiation absorbed and re-emitted by the atmosphere. They can operate in the nadir as shown in Fig. 2, measuring upwelling radiation, or in the limb by measuring slantwise through the atmosphere. Solar occultation instruments (not shown in Fig. 2) stare at the Sun through the atmosphere as the orbiting satellite experiences sunrises and sunsets. Limb and solar occultation instruments detect methane in the stratosphere and upper troposphere, but not at lower altitudes because of cloud interferences. Thus, they do not allow direct inference of methane emissions. They are not listed in Table 1 but are referenced in Sect. 3.2 for measuring stratospheric methane.

All instruments launched to date have been in polar sunsynchronous low Earth orbit (LEO), circling the globe at fixed local times of day. They detect methane in the nadir along the orbit track, and most also observe off-nadir (at a cross-track angle) for additional coverage. Unlike other instruments, GHGSat focuses not on global coverage but on specific targets with very fine pixel resolution and limited viewing domains. Geostationary instruments still at the proposal stage would allow a combination of high spatial and temporal resolution over continental-scale domains, and could observe either in the SWIR or in the TIR following the configurations of Fig. 2.

Figure 3 shows typical vertical sensitivities for solar backscatter instruments in the SWIR and for thermal emission instruments in the TIR. Instrument sensitivity extending down to the surface is desirable for inferring methane emissions. This is achieved in the SWIR, where the atmosphere is nearly transparent unless clouds are present (Frankenberg et al., 2005). SWIR instruments measure the total atmospheric column of methane with near-uniform sensitivity in the troposphere. This column measurement can be related to emissions in a manner that is not directly sensitive to local vertical mixing. Measurements in the TIR require a thermal differ-

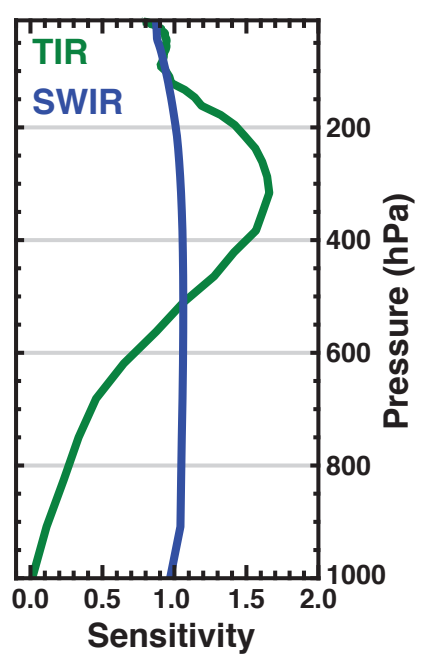

Figure 3. Typical sensitivities as a function of atmospheric pressure for satellite observation of atmospheric methane in the SWIR (solar backscatter) and in the TIR. The sensitivities are the elements of the averaging kernel vector $\boldsymbol{a}$ at different pressure levels (Eq. 1). Adapted from Worden et al. (2015).

ence between the atmosphere and the surface ( $T_{1}$ vs. $T_{o}$ in Fig. 2) and this limits their sensitivity to the middle and upper troposphere. Combination of SWIR and TIR could provide resolution of the lower troposphere but this has not been operationally implemented so far.

Figure 4 shows the atmospheric optical depths of different gases in the SWIR, highlighting the methane absorption bands at 1.65 and $2.3 \mu \mathrm{m}$. The data have been smoothed to $0.1 \mathrm{~nm}$ spectral resolution as is typical of solar backscatter instruments; lidar instruments such as MERLIN can operate with $0.1 \mathrm{pm}$ resolution (Table 1). All solar backscatter instruments so far have operated at $1.65 \mu \mathrm{m}$ but TROPOMI will operate at $2.3 \mu \mathrm{m}$. GOSAT-2 will operate at both. SCIAMACHY was intended to operate at $2.3 \mu \mathrm{m}$ and some retrievals were done in that band (Gloudemans et al., 2008) but an ice layer on the detector decreased performance and the operational retrievals were done at $1.65 \mu \mathrm{m}$ instead. The $2.3 \mu \mathrm{m}$ band is stronger, as shown in Fig. 3, and also allows retrieval of carbon monoxide (CO), which is of interest as an air pollutant and tracer of transport (Worden et al., 2010). However, solar radiation is 3 times weaker at 2.3 than at $1.65 \mu \mathrm{m}$. The $1.65 \mu \mathrm{m}$ band has the advantage that $\mathrm{CO}_{2}$ can also be retrieved, which greatly facilitates the methane retrieval as described below.

Methane retrievals at either 1.65 or $2.3 \mu \mathrm{m}$ fit the reflected solar spectrum measured by the satellite to a modeled spectrum in order to derive the total vertical column density $\Omega$ [molecules $\mathrm{cm}^{-2}$ ] of methane. This approach takes into account the viewing geometry and often includes a prior estimate to regularize the retrieval (Frankenberg et al., 2006; Schepers et al., 2012): 


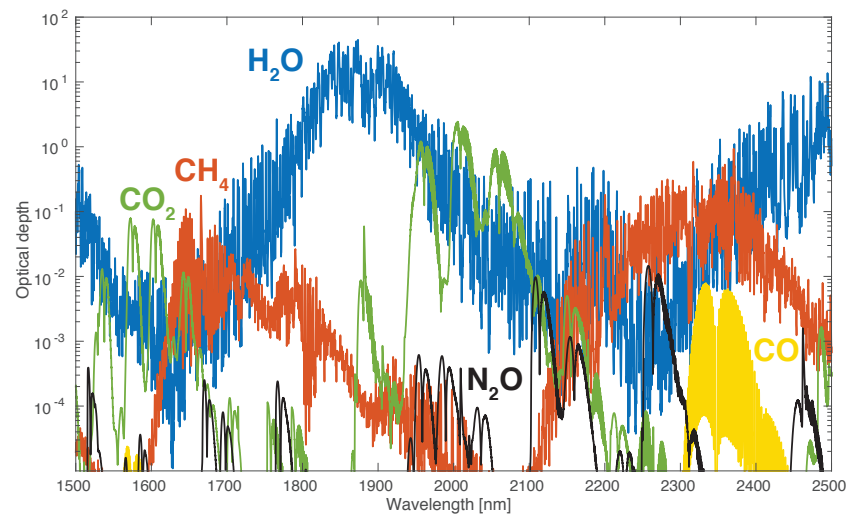

Figure 4. Atmospheric optical depths of major trace gases in the spectral region 1.5-2.5 $\mu \mathrm{m}$. The calculation is for the US Standard Atmosphere (Anderson et al., 1986) with surface concentrations adjusted to $399 \mathrm{ppm} \mathrm{CO}_{2}, 1.9 \mathrm{ppm}$ methane, $330 \mathrm{ppb} \mathrm{N}_{2} \mathrm{O}$, and $80 \mathrm{ppb}$ CO. The line-by-line data have been smoothed with a spectral resolution of $0.1 \mathrm{~nm}$ (full width at half maximum).

$\hat{\Omega}=\Omega_{\mathrm{A}}+\boldsymbol{a}^{T}\left(\omega-\omega_{\mathrm{A}}\right)$.

Here $\hat{\Omega}$ is the retrieved vertical column density, $\Omega_{\mathrm{A}}$ is the prior best estimate assumed in the retrieval, $\omega_{\mathrm{A}}$ is a vector of prior estimates of partial columns [molecules $\mathrm{cm}^{-2}$ ] at successive altitudes summing up to $\Omega_{\mathrm{A}}$, and $\omega$ is the vector of true values for these partial columns. The column averaging kernel vector $\boldsymbol{a}$ expresses the sensitivity of the measurement as a function of altitude (Fig. 3) and is the reduced expression of an averaging kernel matrix that describes the ability of the retrieval to fit not only $\omega$ but other atmospheric and spectroscopic variables as well (Frankenberg et al., 2005; Schepers et al., 2012). The elements of $\boldsymbol{a}$ have values near unity through the depth of the troposphere at either 1.65 or $2.3 \mu \mathrm{m}$ (Fig. 3), meaning that SWIR instruments are sensitive to the full column of methane and that the prior estimates do not contribute significantly to the retrieved columns.

The viewing geometry of the satellite measurement is defined by the solar zenith angle $\theta$ and the satellite viewing angle $\theta_{\mathrm{v}}$ (Fig. 2). This defines a geometric air mass factor $\left(\cos ^{-1} \theta+\cos ^{-1} \theta_{\mathrm{v}}\right)$ for the slant column path of the solar radiation propagating through the atmosphere and reflected to the satellite. Division by this air mass factor converts the slant column obtained by fitting the backscattered spectrum to the actual vertical column, assuming that the incident and reflected solar beams sample the same methane concentrations. This assumption is adequate for pixel sizes larger than $1 \mathrm{~km}$ but breaks down when observing methane plumes at smaller pixel sizes, as discussed in Sect. 4.

The methane vertical column density $\Omega$ is sensitive to changes in surface pressure from topography and weather, affecting the total amount of air in the column. This dependence can be removed by converting $\Omega$ to a dry- air column-average mole fraction $\mathrm{X}=\Omega / \Omega_{\mathrm{a}}$ (also called column-average mixing ratio) where $\Omega_{\mathrm{a}}$ is the vertical column density of dry air as determined from the local surface pressure and humidity. $\mathrm{X}$ is a preferred measure of the methane concentration because it is insensitive to changes in pressure and humidity.

Solar backscatter measurements in the SWIR require a reflective surface. This largely limits the measurements to land, although some ocean data can be obtained from specular reflection at the ocean surface (sun glint). Clouds affect the retrieval by reflecting solar radiation back to space and preventing detection of the air below the cloud. Even partly cloudy scenes are problematic because the highly reflective cloudy fraction contributes disproportionately to the total backscattered radiation from the pixel. A major advantage of finer pixel resolution is thus to increase the probability of clear-sky scenes (Remer et al., 2012). The GOSAT retrievals exclude cloudy scenes by using a simultaneous retrieval of the oxygen column in the $0.76 \mu \mathrm{m} A$ band. A low oxygen column indicates the presence of clouds. For SCIAMACHY this is impractical because the pixel resolution is so coarse $\left(30 \times 60 \mathrm{~km}^{2}\right)$ that a clear-sky requirement would exclude too much data; instead the retrieval allows for partly cloudy scenes (Frankenberg et al., 2006). The fraction of successful retrievals is $17 \%$ for GOSAT (Parker et al., 2011, retrieval) and 9\% for SCIAMACHY (Frankenberg et al., 2011, retrieval), largely limited by cloud cover. TROPOMI retrievals will exclude cloudy scenes by using cloud observations from the VIIRS solar backscatter instrument flying in formation and viewing the same scenes at fine pixel resolution (Veefkind et al., 2012).

Two different methods have been used for methane retrievals at $1.65 \mu \mathrm{m}$ (SCIAMACHY, GOSAT): the $\mathrm{CO}_{2}$ proxy method (Frankenberg et al., 2005) and the full-physics method (Butz et al., 2010). In the full-physics method, the scattering properties of the surface and the atmosphere are fitted as part of the retrieval, using additional fitting variables to describe the scattering. In the $\mathrm{CO}_{2}$ proxy method, the spectral fit for methane ignores atmospheric scattering, and the resulting methane column is subsequently corrected for scattering by using a separate retrieval of $\mathrm{CO}_{2}$ (also ignoring atmospheric scattering) in its nearby $1.6 \mu \mathrm{m}$ absorption band as shown in Fig. 4. This assumes that atmospheric scattering affects the light paths for methane and $\mathrm{CO}_{2}$ retrievals in the same way (since the wavelengths are nearby and absorption strengths are similar). It also assumes that the dry-air column mole fraction of $\mathrm{CO}_{2}$ is known (it is far less variable than for methane). The dry-air column mole fraction of methane is then obtained by scaling to the $\mathrm{CO}_{2}$ retrieval:

$\mathrm{X}_{\mathrm{CH}_{4}}=\left(\frac{\Omega_{\mathrm{CH}_{4}}}{\Omega_{\mathrm{CO}_{2}}}\right) \mathrm{X}_{\mathrm{CO}_{2}}$.

Here $\mathrm{X}_{\mathrm{CO}_{2}}$ is taken from independent information such as the CarbonTracker data assimilation product (Peters et al., 2007) or a multi-model ensemble (Parker et al., 2015). An advan- 

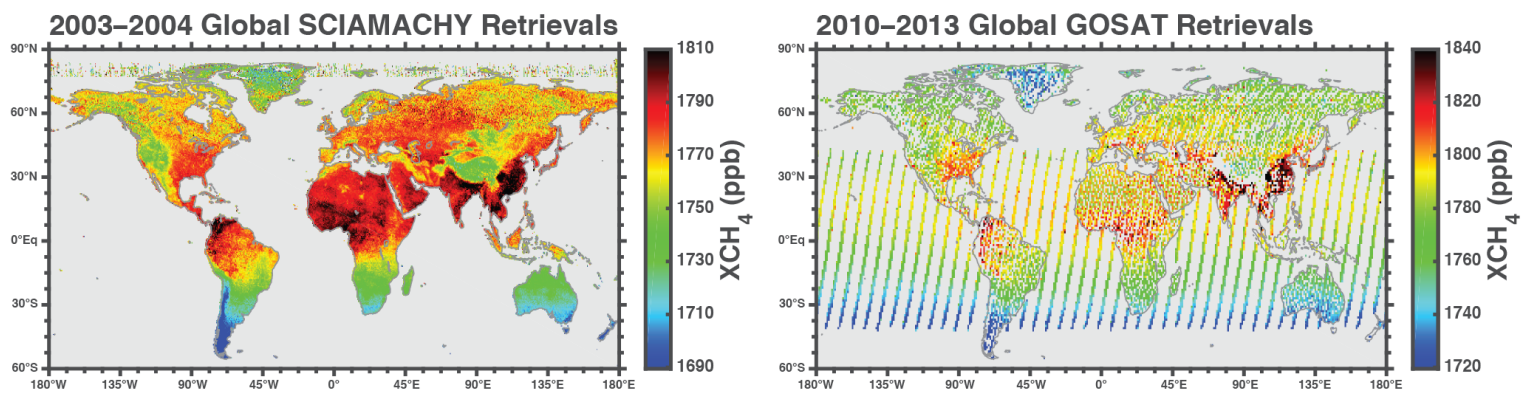

2003-2004 US SCIAMACHY Retrievals

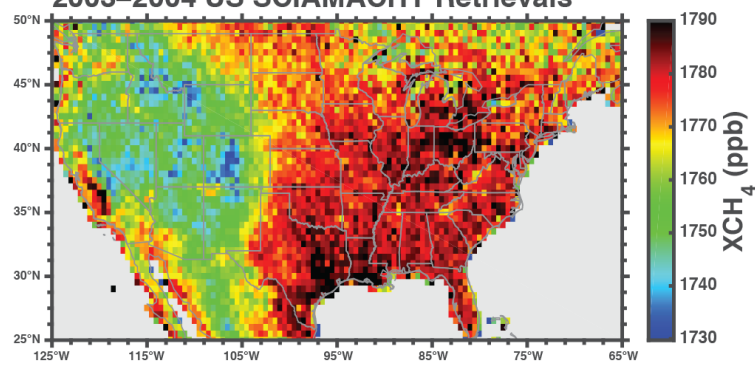

2010-2013 US GOSAT Retrievals

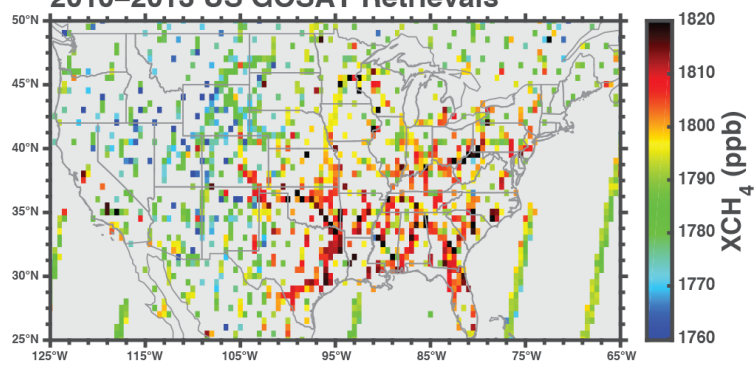

Figure 5. Global and US distributions of methane dry-air column mole fractions $\left(\mathrm{X}_{\mathrm{CH}_{4}}\right)$ observed by SCIAMACHY and GOSAT. Values are annual means for 2003-2004 (SCIAMACHY) and 2010-2013 (GOSAT), using the $\mathrm{CO}_{2}$ proxy retrievals from Frankenberg et al. (2011) for SCIAMACHY and Parker et al. (2011) for GOSAT. GOSAT includes observations of sun glint over the oceans. The color bar is shifted by $30 \mathrm{ppb}$ between the SCIAMACHY and GOSAT panels to account for the global growth of methane from 2003-2004 to 2010-2013. All data are plotted on a $0.5^{\circ} \times 0.5^{\circ}$ grid except for the GOSAT global panel where a $1^{\circ} \times 1^{\circ}$ grid is used to improve visibility.

tage of the $\mathrm{CO}_{2}$ proxy method is that it corrects for instrument biases affecting both methane and $\mathrm{CO}_{2}$. A drawback is that errors in $\mathrm{X}_{\mathrm{CO}_{2}}$ propagate to $\mathrm{X}_{\mathrm{CH}_{4}}$. Comparisons of retrievals using the full-physics and $\mathrm{CO}_{2}$ proxy methods show that they are of comparable quality (Buchwitz et al., 2015) but the $\mathrm{CO}_{2}$ proxy method is much more computationally efficient (Schepers et al., 2012). The $\mathrm{CO}_{2}$ proxy method can be problematic for methane plumes with joint enhancements of $\mathrm{CO}_{2}$, such as from megacities or open fires, that would not be resolved in the independent information for $\mathrm{X}_{\mathrm{CO}_{2}}$. Uncertainties in $\mathrm{X}_{\mathrm{CO}_{2}}$ can be circumvented by using the $\mathrm{X}_{\mathrm{CH}_{4}} / \mathrm{X}_{\mathrm{CO}_{2}}$ ratio as an observed variable in a joint inversion of methane and $\mathrm{CO}_{2}$ surface fluxes (Fraser et al., 2014; Pandey et al., 2015).

Figure 5 shows the global and US distributions of methane $\left(\mathrm{X}_{\mathrm{CH}_{4}}\right)$ observed by SCIAMACHY (2003-2004) and GOSAT (2010-2013). We focus on 2003-2004 for SCIAMACHY because of radiation-induced detector degradation after 2005 (Kleipool et al., 2007). Global methane concentrations increased by $30 \mathrm{ppb}$ from 2003-2004 to 2010-2013 (Hartmann et al., 2013), and the color scale in Fig. 5 is correspondingly shifted to facilitate pattern comparisons. Observations are mainly restricted to land but GOSAT also observes sun glint over the oceans. SCIAMACHY provides full global mapping, while GOSAT only observes at selected pixel locations leaving gaps between pixels. Low values of $\mathrm{X}_{\mathrm{CH}_{4}}$ over elevated terrain (Greenland, Himalayas,
US Intermountain West) reflect a larger relative contribution of the stratosphere (with lower methane) to the total atmospheric column. SCIAMACHY has positive biases over the Sahara and at high latitudes (Sect. 2.2).

The SCIAMACHY and GOSAT global distributions show commonality in patterns. Values are highest in East Asia, consistent with the Emissions Database for Global Atmospheric Research (EDGAR) inventory (European Commission, 2011), where the dominant contributions are from rice cultivation, livestock, and coal mining. Values are also high over central Africa and northern South America because of wetlands and livestock. Over the US, both SCIAMACHY and GOSAT feature high values in the South Central US (oilgas, livestock) and hotspots in the Central Valley of California and in eastern North Carolina (livestock). There are also high values in the Midwest that are less consistent between the two sensors and could be due to a combination of oil-gas, livestock, and coal mining sources.

TROPOMI will observe methane in the $2.3 \mu \mathrm{m}$ band in order to also retrieve CO. Retrieval at $2.3 \mu \mathrm{m}$ does not allow the $\mathrm{CO}_{2}$ proxy method because no neighboring $\mathrm{CO}_{2}$ band is available (Fig. 4). Retrievals of methane from TROPOMI will therefore rely on the full-physics method. The operational retrieval for TROPOMI is described by Butz et al. (2012), who find that the precision is almost always better than $1 \%$ and that over $90 \%$ of cloud-free scenes can be successfully retrieved. Observations of methane-CO corre- 
lations from joint $2.3 \mu \mathrm{m}$ retrievals may provide useful additional information for inferring methane sources (Xiao et al., 2004; Wang et al., 2009; Worden et al., 2013).

Observations of methane in the TIR are available from the IMG, AIRS, TES, IASI, and CrIS instruments (Table 1). These instruments observe the temperature-dependent blackbody radiation emitted by the Earth and its atmosphere. Atmospheric methane absorbs upwelling radiation in a number of bands around $8 \mu \mathrm{m}$ and re-emits it at a colder temperature. The methane concentration is retrieved from the temperature contrast. TIR instruments have little sensitivity to the lower troposphere because of insufficient temperature contrast with the surface, as illustrated in Fig. 3. This makes them less useful for detecting local/regional methane emissions. Conversely, they observe both day and night, over land and ocean, and provide concurrent retrievals of other trace gases such as $\mathrm{CO}$ and ammonia that can be correlated with methane. Worden et al. (2013) showed that TIR measurements can be particularly effective at quantifying methane emissions from open fires, because aerosol interference is negligible in the TIR and concurrent retrieval of $\mathrm{CO}$ allows inference of the methane-CO emission factor.

Multispectral retrievals in the SWIR and TIR combine the advantages of both approaches and provide some vertical profile information, as demonstrated by Herbin et al. (2013) using the combination of SWIR and TIR data from GOSAT, and by Worden et al. (2015) using the combination of SWIR from GOSAT and TIR from TES. This could enable separation between the local/regional methane enhancement near the surface and the higher-altitude methane background (Bousserez et al., 2015). Such multi-spectral retrievals are not yet produced operationally because of computational requirements and because of limitations in the quality and calibration of spectra across different detectors (Hervé Herbin, personal communication, 2016).

The MERLIN lidar instrument scheduled for launch in 2020 (Kiemle et al., 2011) will measure methane in the pencil of $1.65 \mu \mathrm{m}$ radiation emitted by a laser along the satellite track and reflected directly back to the satellite. It will observe the full vertical column of methane during day and night, over both land and oceans, and will have unique capability for observing high latitudes during the dark season. By measuring only the direct reflected radiation it will not be affected by scattering errors, unlike the passive SWIR instruments, and cloud interferences will be minimized. Kiemle et al. (2014) show that monthly and spatial averaging of the MERLIN data on a $50 \times 50 \mathrm{~km}^{2}$ grid should provide global mapping of methane concentrations with $1-2 \%$ precision.

Other instruments in Table 1 are presently at the proposal stage. All use solar backscatter. CarbonSat (Buchwitz et al., 2013) is designed to measure methane globally with an unprecedented combination of fine pixel resolution $\left(2 \times 2 \mathrm{~km}^{2}\right)$ and high precision $(0.4 \%)$. It was a finalist for the ESA's Earth Explorer Program in 2015. GEO-CAPE (Fishman et al., 2012), GeoFTS (Xi et al., 2015), geoCARB (Polonsky et al., 2014), and G3E (Butz et al., 2015) are geostationary instruments focused on mapping the continental scale with $2-5 \mathrm{~km}$ resolution. Geostationary capabilities are discussed further in Sect. 4.

\subsection{Error characterization}

Satellite observations require careful calibration and error characterization for use in inverse analyses. Errors may arise from light collection by the instrument, dark current, spectroscopic data, the radiative transfer model, cloud contamination, and other factors. Kuze et al. (2016) give a detailed description of GOSAT instrument errors as informed by 5 years of operation. Errors may be random, such as from photon count statistics, or systematic, such as from inaccurate spectroscopic data. They may increase with time due to instrument degradation.

Random error (precision) and systematic error (accuracy) have very different impacts (Kulawik et al., 2016). Random error can be reduced by repeated observations and averaging. As we will illustrate in Sect. 4, instrument precision can define the extent of spatial/temporal averaging required for satellite observations to usefully quantify emissions. Systematic error, on the other hand, is irreducible and propagates in the inversion to cause a corresponding bias in the emission estimates. A uniform global bias is not problematic for methane since the global mean concentration is well known from surface observations, but a spatially variable bias affects source attribution by aliasing the methane enhancements relative to background. Buchwitz et al. (2015) refer to this spatial variability in the bias as "relative bias". It can arise, for example, from different surface reflectivity, aerosol interference, sloping terrain, or unresolved variability in $\mathrm{CO}_{2}$ columns when using the $\mathrm{CO}_{2}$ proxy method (Schepers et al., 2012; Alexe et al., 2015). Buchwitz et al. (2015) estimate threshold requirements of $34 \mathrm{ppb}$ single-observation precision and $10 \mathrm{ppb}$ relative bias for solar backscatter satellite observations to be useful in inversions of methane emissions on regional scales.

Validation of satellite data requires accurate suborbital observations of methane from surface sites, aircraft, or balloons. Direct validation involves comparison of single-scene satellite retrievals to suborbital observations of that same scene. The suborbital observations must be collocated in space and time with the satellite overpass, and they must provide a full characterization of the column as observed by the satellite. Although direct validation is the preferred means of validation, the requirements greatly limit the conditions under which it can be done. Indirect validation is a complementary method that involves diagnosing the consistency between satellite and suborbital data when compared to a global 3-D CTM as a common intercomparison platform (Zhang et al., 2010). It considerably increases the range of suborbital measurements that can be used because collocation in space and time is not required. Indirect validation can also be con- 
ducted formally by chemical data assimilation of the different observational data streams into the CTM.

The standard benchmark for direct validation of solar backscatter satellite observations is the worldwide Total Carbon Column Observing Network (TCCON) (Wunch et al., 2011). TCCON consists of ground-based Fourier transform spectrometer (FTS) instruments staring at the Sun and detecting methane absorption in the direct solar radiation spectrum. This measures the same dry-air column mole fraction $\mathrm{X}_{\mathrm{CH}_{4}}$ as the satellite but with a much better signal-to-noise ratio and a well-defined light path. The TCCON retrieval of methane is calibrated to the World Meteorological Organization (WMO) scale and has been validated by comparison to aircraft profiles (Wunch et al., 2011). The single-observation precision and bias for $\mathrm{X}_{\mathrm{CH}_{4}}$ are both about $4 \mathrm{ppb}$ (Buchwitz et al., 2015).

Dils et al. (2014) and Buchwitz et al. (2015) present direct validation of the different operational SCIAMACHY and GOSAT retrievals using TCCON data. Relative bias is determined using pairs of TCCON sites. They find a single-observation precision of $30 \mathrm{ppb}$ and a relative bias of 4-13 ppb for SCIAMACHY in 2003-2005, which are good enough for inverse applications, but they worsen after 2005 to $50-82 \mathrm{ppb}$ (precision) and $15 \mathrm{ppb}$ (relative bias). For GOSAT, they report single-observation precisions of 12 $13 \mathrm{ppb}$ for the $\mathrm{CO}_{2}$ proxy products and $15-16 \mathrm{ppb}$ for the full-physics products. Relative biases for GOSAT are 2$3 \mathrm{ppb}$ for the $\mathrm{CO}_{2}$ proxy products and 3-8 ppb for the fullphysics products. Thus, the GOSAT data are of high quality for use in inversions. The $\mathrm{CO}_{2}$ proxy retrievals provide a much higher density of observations than the full-physics retrievals, so that random errors can be effectively decreased and the precision can be improved through temporal averaging.

TIR measurements are most sensitive to the middle-upper troposphere (Fig. 3) and aircraft vertical profiles provide the best resource for direct validation. Wecht et al. (2012) and Alvarado et al. (2015) evaluated successive versions of TES methane retrievals with data from the HIPPO pole-to-pole aircraft campaigns over the Pacific (Wofsy, 2011). Alvarado et al. (2015) report that the latest Version 6 of the TES product has a bias of $4.8 \mathrm{ppb}$. Crevoisier et al. (2013) find that IASI observations are consistent with aircraft observations to within $5 \mathrm{ppb}$.

Use of satellite observations in inverse modeling studies cannot simply rely on past validation to quantify the instrument error. This is because the instrument calibration may drift with time, optics and detectors may degrade, and errors may vary depending on surface and atmospheric conditions. It is essential that error characterization be done for the specific temporal and spatial window of the inversion. Opportunities for direct validation may be sparse but indirect validation with the CTM to be used for the inversion is particularly effective. Such indirect validation can exploit all relevant suborbital data collected in the window to assess their consistency with the satellite data. This has been standard practice in inversions of SCIAMACHY and GOSAT data and has resulted in correction factors applied to the data as a function of latitude (Bergamaschi et al., 2009, 2013; Fraser et al., 2013; Alexe et al., 2015; Turner et al., 2015), water vapor (Houweling et al., 2014; Wecht et al., 2014a), or air mass factor (Cressot et al., 2014).

\section{Inferring methane emissions from satellite data}

\subsection{Overview of inverse methods}

The general approach for inferring methane emissions from observed atmospheric concentrations is to use a 3-D CTM describing the sensitivity of concentrations to emissions. The CTM simulates atmospheric transport on the basis of assimilated meteorological data for the observation period and a 2-D field of gridded emissions. It computes concentrations as a function of emissions by solving the mass continuity equation that describes the change in the 3-D concentration field resulting from emissions, winds, turbulence, and chemical loss. In Eulerian CTMs, the solution to the continuity equation is done on a fixed atmospheric grid. In Lagrangian CTMs, often called Lagrangian particle dispersion models (LPDMs), the solution is obtained by tracking a collection of air particles moving with the flow. Eulerian models have the advantage of providing a complete, continuous, and massconserving representation of the atmosphere. LPDMs have the advantage of being directly integrable backward in time, so that the source footprint contributing to the concentrations at a particular receptor point is economically computed. Eulerian models can also be integrated backward in time to derive source footprints by using the model adjoint (Henze et al., 2007). LPDMs have been used extensively for inverse analyses of ground and aircraft methane observations, where the limited number of receptor points makes the Lagrangian approach very efficient (Miller et al., 2013; Ganesan et al., 2015; Henne et al., 2016). Satellite observations involve a considerably larger number of receptor points, including different altitudes contributing to the column measurement. For this reason, all published inversions of satellite methane data so far have used Eulerian CTMs. A preliminary study by Benmergui et al. (2015) applies an LPDM to inversion of GOSAT data.

The CTM provides the sensitivity of concentrations to emissions at previous times. By combining this information with observed concentrations we can solve for the emissions needed to explain the observations. Because of errors in measurements and in model transport, the best that can be achieved is an error-weighted statistical fit of emissions to the observations. This must account for prior knowledge of the distribution of emissions, generally from a bottom-up inventory, in order to target the fit to the most relevant emis- 
sion variables and in order to achieve an optimal estimate of emissions consistent with all information at hand.

The standard method for achieving such a fit is Bayesian optimization. The emissions are assembled into a state vector $\boldsymbol{x}(\operatorname{dim} n)$, and the observations are assembled into an observation vector $\boldsymbol{y}(\operatorname{dim} m)$. Bayes' theorem gives

$P(\boldsymbol{x} \mid \boldsymbol{y})=\frac{P(\boldsymbol{x}) P(\boldsymbol{y} \mid \boldsymbol{x})}{P(\boldsymbol{y})}$,

where $P(\boldsymbol{x})$ and $P(\boldsymbol{y})$ are the probability density functions (PDFs) of $\boldsymbol{x}$ and $\boldsymbol{y}, P(\boldsymbol{x} \mid \boldsymbol{y})$ is the conditional PDF of $\boldsymbol{x}$ given $\boldsymbol{y}$, and $P(\boldsymbol{y} \mid \boldsymbol{x})$ is the conditional PDF of $\boldsymbol{y}$ given $\boldsymbol{x}$. We recognize here $P(\boldsymbol{x})$ as the prior PDF of $\boldsymbol{x}$ before the observations $\boldsymbol{y}$ have been made, $P(\boldsymbol{y} \mid \boldsymbol{x})$ as the observation PDF given the true value of $\boldsymbol{x}$ (for which the observations were made), and $P(\boldsymbol{x} \mid \boldsymbol{y})$ as the posterior PDF of $\boldsymbol{x}$ after the observations $\boldsymbol{y}$ have been made. The optimal estimate of emissions is defined by the maximum of $P(\boldsymbol{x} \mid \boldsymbol{y})$, which we obtain by solving $\nabla_{\boldsymbol{x}} P(\boldsymbol{x} \mid \boldsymbol{y})=\mathbf{0}$.

In the absence of better information, error PDFs are often assumed to be Gaussian (Rodgers, 2000). We then have

$$
\begin{gathered}
P(\boldsymbol{x})=\frac{1}{(2 \pi)^{n / 2}\left|\mathbf{S}_{\mathrm{A}}\right|^{1 / 2}} \\
\exp \left[-\frac{1}{2}\left(\boldsymbol{x}-\boldsymbol{x}_{\mathrm{A}}\right)^{\mathrm{T}} \mathbf{S}_{\mathrm{A}}^{-1}\left(\boldsymbol{x}-\boldsymbol{x}_{\mathrm{A}}\right)\right], \\
P(\boldsymbol{y} \mid \boldsymbol{x})=\frac{1}{(2 \pi)^{m / 2}\left|\mathbf{S}_{\mathrm{O}}\right|^{1 / 2}} \\
\exp \left[-\frac{1}{2}(\boldsymbol{y}-F(\boldsymbol{x}))^{\mathrm{T}} \mathbf{S}_{\mathrm{O}}^{-1}(\boldsymbol{y}-F(\boldsymbol{x}))\right],
\end{gathered}
$$

where $\boldsymbol{x}_{\mathrm{A}}$ is the prior estimate, $\mathbf{S}_{\mathrm{A}}$ is the associated prior error covariance matrix, $F$ is the CTM solving for $\boldsymbol{y}=F(\boldsymbol{x})$ and is called the forward model for the inversion, and $\mathbf{S}_{\mathrm{O}}$ is the observational error covariance matrix including contributions from measurement and CTM errors. An important assumption here is that the observational error is random; any known systematic bias in the measurement or the CTM must be corrected before the inversion is conducted. This requires careful validation (Sect. 2.2).

The optimization problem $\nabla_{x} P(\boldsymbol{x} \mid \boldsymbol{y})=0$ is solved by minimizing the cost function $J(x)$ :

$$
\begin{aligned}
& J(x)=\left(x-x_{\mathrm{A}}\right)^{\mathrm{T}} \mathbf{S}_{\mathrm{A}}^{-1}\left(\boldsymbol{x}-\boldsymbol{x}_{\mathrm{A}}\right) \\
& +(\boldsymbol{y}-F(\boldsymbol{x}))^{\mathrm{T}} \mathbf{S}_{\mathrm{O}}^{-1}(\boldsymbol{y}-F(\boldsymbol{x})),
\end{aligned}
$$

where the PDFs have been converted to their logarithms and the terms independent of $\boldsymbol{x}$ have been discarded. In particular, $P(\boldsymbol{y})$ in Eq. (3) is discarded since it does not depend on $\boldsymbol{x}$. The minimum of $J$ is found by differentiating Eq. (6):

$\nabla_{x} J(x)=2 \mathbf{S}_{\mathrm{A}}^{-1}\left(\boldsymbol{x}-\boldsymbol{x}_{\mathrm{A}}\right)+2 \mathbf{K}^{\mathrm{T}} \mathbf{S}_{\mathrm{O}}^{-1}(F(\boldsymbol{x})-\boldsymbol{y})=0$,

where $\mathbf{K}=\nabla_{x} F=\partial \boldsymbol{y} / \partial \boldsymbol{x}$ is the Jacobian of $F$ and $\mathbf{K}^{\mathrm{T}}$ is its adjoint.

\subsubsection{Analytical method}

Equation (7) can be solved analytically if the relationship between emissions and atmospheric concentrations is linear, such that $F(\boldsymbol{x})=\mathbf{K} \boldsymbol{x}+\boldsymbol{c}$ where $\boldsymbol{c}$ is a constant. This is the case for methane if the tropospheric $\mathrm{OH}$ concentration field used in the CTM to compute methane loss is not affected by changes in methane. Although methane and $\mathrm{OH}$ levels are interdependent because methane is a major $\mathrm{OH}$ sink (Prather, 1996), the global methane loading relevant for computing $\mathrm{OH}$ concentrations is well known (Prather et al., 2012). It is therefore totally appropriate to treat $\mathrm{OH}$ concentrations as decoupled from methane in the inversion. Analytical solution of Eq. (7) for a linear model $\boldsymbol{y}=F(\boldsymbol{x})$ (where the constant $c$ can be simply subtracted from the observations) yields an optimal estimate $\hat{\boldsymbol{x}}$ with Gaussian error characterized by an error covariance matrix $\hat{\mathbf{S}}$ (Rodgers, 2000):

$\hat{\boldsymbol{x}}=\boldsymbol{x}_{\mathrm{A}}+\mathbf{G}\left(\boldsymbol{y}-\mathbf{K} \boldsymbol{x}_{\mathrm{A}}\right)$

$\hat{\mathbf{S}}=\left(\mathbf{K}^{\mathrm{T}} \mathbf{S}_{\mathrm{O}}^{-1} \mathbf{K}+\mathbf{S}_{\mathrm{A}}^{-1}\right)^{-1}$.

Here $\mathbf{G}$ is the gain matrix given by

$\mathbf{G}=\mathbf{S}_{\mathrm{A}} \mathbf{K}^{\mathrm{T}}\left(\mathbf{K S}_{\mathrm{A}} \mathbf{K}^{\mathrm{T}}+\mathbf{S}_{\mathrm{O}}\right)^{-1}$.

The degree to which the observations constrain the state vector of emissions is diagnosed by the averaging kernel matrix $\mathbf{A}=\partial \hat{\boldsymbol{x}} / \partial \boldsymbol{x}=\mathbf{G K}=\mathbf{I}_{n}-\hat{\mathbf{S}} \mathbf{S}_{\mathrm{A}}^{-1}$, expressing the sensitivity of the optimized estimate to the actual emissions $\boldsymbol{x}$. Here $\mathbf{I}_{n}$ is the $n \times n$ identity matrix. The observations may adequately constrain some features of the emission field and not others. The number of independent pieces of information on the emission field provided by the observing system is given by the trace of $\mathbf{A}$ and is called the degrees of freedom for signal $(\mathrm{DOFS}=\operatorname{tr}(\mathbf{A}))$.

Analytical solution to the inverse problem provides full error characterization of the solution through $\hat{\mathbf{S}}$ and $\mathbf{A}$. This is a very attractive feature, particularly for an underconstrained problem where we need to understand what information the observations actually provide. However, it requires explicit construction of the Jacobian matrix. With a Eulerian CTM this requires $n$ individual simulations, each providing a column $j$ of the Jacobian $\partial \boldsymbol{y} / \partial x_{j}$. With an LPDM (or the adjoint of a Eulerian CTM), this requires $m$ individual simulations tracking the backward transport from a given observation location and providing a row $i$ of the Jacobian $\partial y_{i} / \partial \boldsymbol{x}$. Either way is a computational challenge when using a very large number $m$ of satellite observations to optimize a very large number $n$ of emission elements with high resolution.

Equations (8)-(10) further require the multiplication and inversion of large matrices of dimensions $m$ and $n$. This curse of dimensionality can be alleviated by ingesting the observations sequentially as uncorrelated data packets (thus effectively reducing $\mathrm{m}$ ) (Rodgers, 2000) and by recognizing that individual state vector elements have only a limited zone of influence on the observations (thus effectively reducing $n$ 
or taking advantage of sparse-matrix methods) (Bui-Thanh et al., 2012). When observations are ingested sequentially for successive time periods, with each packet used to update emissions for the corresponding period, we refer to the method as a Kalman filter.

There is danger in over-interpreting the posterior error covariance matrix $\hat{\mathbf{S}}$ when the number of observations is very large, as from a satellite data set, because of the implicit assumption that observational errors are truly random and are representatively sampled over the PDF. CTM errors are rarely unbiased and generally not representatively sampled. Thus, $\hat{\mathbf{S}}$ tends to be an over-optimistic characterization of the error on the optimal estimate. An alternate approach for error characterization is to compute an ensemble of solutions with modified prior estimates, forward model, inverse methods, or error estimates (Heald et al., 2004; Henne et al., 2016).

\subsubsection{Adjoint method}

The limitation on the size of the emission state vector can be lifted by solving Eq. (7) numerically instead of analytically. This is done by applying iteratively the adjoint of the CTM, which is the model operator $\mathbf{K}^{\mathrm{T}}$, to the error-weighted model-observation differences $\mathbf{S}_{\mathrm{O}}^{-1}(F(\boldsymbol{x})-\boldsymbol{y})$. We discussed above how this backward transport provides the sensitivity of concentrations to emissions at prior times, i.e., the footprint of the concentrations. Here we apply it to determine the footprint of the errors in emissions as diagnosed by the model-observation differences. For a Eulerian CTM the adjoint must be independently constructed (Henze et al., 2007), while for a LPDM it is simply obtained by transporting the air particles backward in time.

The iterative procedure in the adjoint method is as follows. Starting from the prior estimate $\boldsymbol{x}_{\mathrm{A}}$ as an initial guess, we apply the adjoint operator $\mathbf{K}^{\mathrm{T}}$ to the error-weighted modelobservation differences $\mathbf{S}_{\mathrm{O}}^{-1}\left(F\left(\boldsymbol{x}_{\mathrm{A}}\right)-\boldsymbol{y}\right)$ and in this manner determine the sensitivity of these differences to emissions earlier in time; this defines the cost function gradient $\nabla_{x} J\left(\boldsymbol{x}_{\mathrm{A}}\right)$ in Eq. (7). By applying $\nabla_{x} J\left(\boldsymbol{x}_{\mathrm{A}}\right)$ to $\boldsymbol{x}_{\mathrm{A}}$ with a steepest-descent algorithm we obtain a next guess $x_{1}$ for the minimum of $J(\boldsymbol{x})$, compute the corresponding vector $\mathbf{K}^{\mathrm{T}} \mathbf{S}_{\mathrm{O}}^{-1}\left(F\left(\boldsymbol{x}_{1}\right)-\boldsymbol{y}\right)$, and add the error-weighted difference from the prior estimate $\mathbf{S}_{\mathrm{A}}^{-1}\left(\boldsymbol{x}_{1}-\boldsymbol{x}_{\mathrm{A}}\right)$ to obtain the cost function gradient $\nabla_{x} J\left(x_{1}\right)$. By applying $\nabla_{x} J\left(x_{1}\right)$ to $x_{1}$ with the steepest-descent algorithm we obtain a next guess $x_{2}$, and iterate in this manner to find the minimum of $J(x)$ (Henze et al., 2007). A major advantage of the adjoint method is that the Jacobian is never explicitly computed, and there are no multiplication or inversion operations involving large matrices. Thus, there is no computational limitation on the dimension of $\boldsymbol{x}$. Another major advantage is that the error PDFs do not need to be Gaussian. A drawback is that error characterization is not included as part of the solution. Approximate methods are available at additional computational cost to es- timate the posterior error covariance matrix $\hat{\mathbf{S}}$ and from there the averaging kernel matrix A (Bousserez et al., 2015).

\subsubsection{MCMC methods}

Markov Chain Monte Carlo (MCMC) methods are yet another approach to solving the Bayesian inverse problem. Here the posterior PDF $P(\boldsymbol{x} \mid \boldsymbol{y})$ is constructed by direct computation from Eq. (3) using stochastic sampling of the $\boldsymbol{x}$ domain and with any chosen forms for $P(\boldsymbol{x})$ and $P(\boldsymbol{y} \mid \boldsymbol{x})$. Starting from the prior estimate $\boldsymbol{x}_{\mathrm{A}}$, we compute $P\left(\boldsymbol{x}_{\mathrm{A}}\right)$ and $P\left(\boldsymbol{y} \mid \boldsymbol{x}_{\mathrm{A}}\right)$, and from there compute $P\left(\boldsymbol{x}_{\mathrm{A}} \mid \boldsymbol{y}\right)$ using Eq. (3). We then define the next element of the Markov chain as $\boldsymbol{x}_{1}=\boldsymbol{x}_{\mathrm{A}}+\Delta \boldsymbol{x}$, where $\Delta \boldsymbol{x}$ is a random increment, compute $P\left(\boldsymbol{x}_{1} \mid \boldsymbol{y}\right)$, and so on. With a suitable algorithm to sample representatively the $\boldsymbol{x}$ domain as successive elements of the Markov chain, the full structure of $P(\boldsymbol{x} \mid \boldsymbol{y})$ is eventually constructed. Miller et al. (2014) and Ganesan et al. (2015) used MCMC methods in regional inversions of suborbital methane data. A major advantage is that the prior and observational PDFs can be of any form. For example, the prior PDF can include a "fat tail" to allow for the possibility of a point source behaving as a "super-emitter" either continuously or sporadically (Zavala-Araiza et al., 2015). Another advantage is that the full posterior PDF of the solution is obtained (not just the optimal estimate). The main drawback is the computational cost of exploring the $n$-dimensional space defined by $\boldsymbol{x}$.

There are other ways of expressing the prior information than as $\left(\boldsymbol{x}_{\mathrm{A}}, \mathbf{S}_{\mathrm{A}}\right)$. In the hierarchical Bayesian approach (Ganesan et al., 2014), information on the prior is optimized as part of the inversion. In the geostatistical approach (Michalak et al., 2004), prior information is expressed in terms of emission patterns rather than magnitudes. The cost function in the geostatistical inversion is

$$
\begin{gathered}
J(\boldsymbol{x}, \boldsymbol{\beta})=(\boldsymbol{x}-\mathbf{P} \boldsymbol{\beta})^{\mathrm{T}} \mathbf{S}^{-1}(\boldsymbol{x}-\mathbf{P} \boldsymbol{\beta}) \\
+(\boldsymbol{y}-F(\boldsymbol{x}))^{\mathrm{T}} \mathbf{S}_{\mathrm{O}}^{-1}(\boldsymbol{y}-F(\boldsymbol{x}))
\end{gathered}
$$

where the $n \times q$ matrix $\mathbf{P}$ describes the different state vector patterns $q$, with each column of $\mathbf{P}$ describing a normalized pattern such as the distribution of livestock. The unknown vector $\boldsymbol{\beta}$ of dimension $q$ gives the mean scaling factor for each pattern. Thus, $\mathbf{P} \boldsymbol{\beta}$ represents a prior model for the mean, with $\boldsymbol{\beta}$ to be optimized as part of the inversion. The covariance matrix $\mathbf{S}$ gives the prior covariance of $\boldsymbol{x}$, rather than the error covariance.

Inverse methods for constraining emissions can be applied not only to current observing systems but also to formally evaluate the capability of a proposed future instrument to improve current knowledge. Given an observational plan and error specifications for the proposed instrument, we can compute the expected observational error covariance matrix $\mathbf{S}_{\mathrm{O}}$. Given the prior estimate $\left(x_{\mathrm{A}}, \mathbf{S}_{\mathrm{A}}\right)$ informed by the current observing system without the proposed instrument, we can quantify the information added by the proposed instrument 
by computing $\hat{\mathbf{S}}$ from Eq. (9) or an adjoint-based approximation (Bousserez et al., 2015). From there we obtain the averaging kernel matrix $\mathbf{A}=\mathbf{I}_{n}-\hat{\mathbf{S}} \mathbf{S}_{\mathrm{A}}^{-1}$ and the DOFS, and compare to the DOFS without the instrument to quantify the information to be gained. This assessment will tend to be optimistic because of the assumption that errors are random, well characterized, and representatively sampled, as discussed above. But at least it demonstrates the potential of the proposed instrument. Applications to methane are presented in Sect. 3.4.

The simple error analysis described above to assess the value of a future instrument is sometimes loosely called an observing system simulation experiment (OSSE). However, the OSSE terminology is generally reserved for a more rigorous test (and an actual "experiment") of the benefit of adding the proposed instrument to the current observing system, including realistic accounting of CTM errors. A standard OSSE setup is illustrated in Fig. 6. The OSSE uses two CTMs driven by different assimilated meteorological datasets for the same period. The first model (CTM1) produces a synthetic 3-D field of atmospheric concentrations from an emission inventory taken as the "true" emissions (A in Fig. 6). For the purpose of the exercise, CTM1 is taken to have no error and so describes the true 3-D field of atmospheric concentrations. This true atmosphere is then sampled synthetically with the current observing system, adding instrument noise as stochastic random error, so that the resulting synthetic data mimic the current observing system. Inversion of these data returns emissions optimized by the current observing system (B in Fig. 6) We then add the proposed instrument to the observing system, again adding instrument noise as random error on the basis of the instrument specifications, and invert the data using the previously optimized emissions (B) as prior estimate. The resulting optimized emissions (C in Fig. 6) can be compared to the "true" emissions (A) and to the prior emissions (B) to quantify the value of the proposed instrument and its advantage relative to the current observing system. The use of two independent assimilated meteorological data sets is important for this exercise as it allows for realistic accounting of the CTM error component. Such an OSSE setup is frequently used to evaluate proposed meteorological instruments, and it has previously been applied to the evaluation of a geostationary instrument for tropospheric ozone (Zoogman et al., 2014) but not so far for methane.

\subsection{Specific issues in applying inverse methods to satellite methane data}

There are a number of issues requiring care in the application of inverse methods to infer methane emissions from observations of atmospheric methane, some of which are specific to satellite observations.

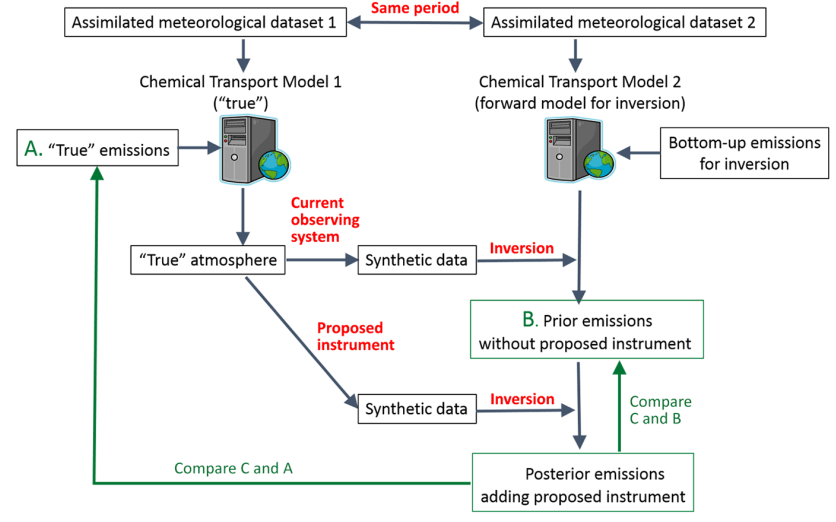

Figure 6. Generic design of an observing system simulation experiment (OSSE) to evaluate the potential of a proposed new atmospheric instrument to improve knowledge of emissions relative to the current observing system.

\subsubsection{Selection of emission state vector}

A first issue relates to the resolution of the emission field (state vector) to be optimized by the inversion. Methane originates from a large number of scattered sources, with emission factors that are poorly known and highly variable for a given source sector. It is therefore of interest to optimize emissions with fine spatial resolution, and for some sources also with fine temporal resolution. The resolution of the emission state vector can in principle be as fine as the grid resolution and time step of the CTM used as a forward model. However, the amount of information contained in the observations places limits on the extent to which emissions can actually be resolved. Satellite data sets may be large but the data are noisy. If the dimension of the emission state vector is too large relative to the information content of the observations, then the Bayesian optimization problem is underconstrained and the solution may be heavily weighted by the prior estimate. This is known as the smoothing error and the associated error covariance matrix is $\left(\mathbf{I}_{n}-\mathbf{A}\right) \mathbf{S}_{\mathrm{A}}\left(\mathbf{I}_{n}-\mathbf{A}\right)^{\mathrm{T}}$ (Rodgers, 2000). Smoothing is not a problem per se if the off-diagonal structure of $\mathbf{S}_{\mathrm{A}}$ is well characterized, so that information can propagate between state vector elements, but it generally is not. When $\mathbf{S}_{\mathrm{A}}$ is specified diagonal, as is often the case, the ability to depart from the prior estimate and reduce the posterior error will be artificially suppressed if the dimension of $\boldsymbol{x}$ is too large (Wecht et al., 2014a).

Figure 7 illustrates the smoothing problem in an inversion of methane emissions over North America using SCIAMACHY. The cure is to reduce the dimension of the emission state vector by aggregating state vector elements and optimizing only the aggregate (Fig. 7). However, this introduces another type of error, known as aggregation error, because the relationship between aggregated state vector elements is now imposed by the prior estimate (Kaminski et al., 2001). As shown by Turner and Jacob (2015) and illus- 


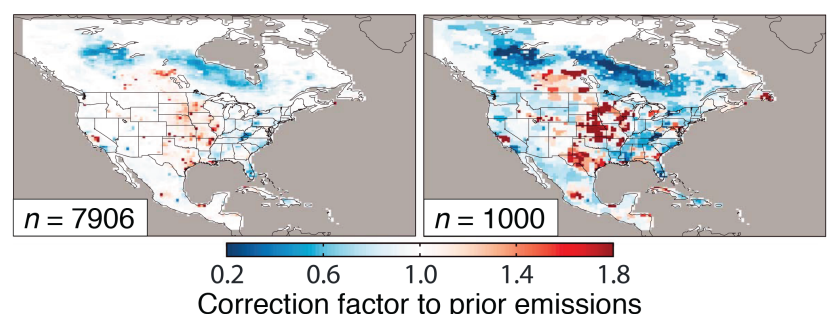

Correction factor to prior emissions
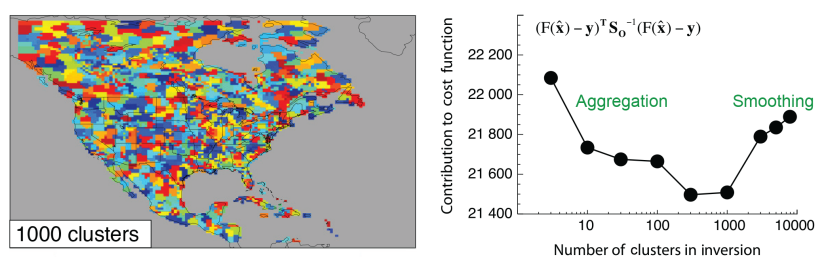

Figure 7. Effect of smoothing and aggregation errors in a highresolution inversion of methane emissions using SCIAMACHY observations of methane columns for summer 2004. The top left panel shows the correction factors to prior emissions when attempting to optimize emissions at the native $1 / 2^{\circ} \times 2 / 3^{\circ}$ grid resolution of the chemical transport model $(n=7906)$. The top right panel shows the same inversion but with a reduced state vector $(n=1000)$ constructed by hierarchical clustering of the native-resolution grid cells (bottom left panel). The bottom right panel shows the ability of the inversion to fit the satellite observations as the state vector dimension is decreased from $n=7906$ to $n=3$ by hierarchical clustering. The quality of the fit is measured by the observational terms of the cost function for the inversion. Optimal results are achieved for $n$ in the range 300-1000. Finer resolution incurs large smoothing errors, while coarser resolution incurs large aggregation errors. Adapted from Wecht et al. (2014a).

trated in Fig. 7, it is possible to define an optimal dimension of the emission state vector by balancing the smoothing and aggregation errors. For a multi-annual GOSAT data set this implies a spatial resolution of the order of $100-1000 \mathrm{~km}$ in methane source regions (Turner et al., 2015). The state vector of emissions can be reduced optimally by hierarchical clustering (Wecht et al., 2014a) or by using radial basis functions with Gaussian PDFs (Turner and Jacob, 2015).

\subsubsection{Bottom-up inventory used as prior estimate}

Inverse analyses require high-quality gridded bottom-up inventories as prior estimates to regularize the solution and interpret results. All inversions of methane satellite data so far have relied on the EDGAR bottom-up inventory for anthropogenic emissions with $0.1^{\circ} \times 0.1^{\circ}$ spatial resolution (European Commission, 2011), which is presently the only global bottom-up inventory available on a fine grid. EDGAR relies on IPCC (2006) default tier 1 methods that are relatively crude and it provides only limited classification of methane emissions by source sector. Alexe et al. (2015) and Turner et al. (2015) find that uncertainties in source patterns in the EDGAR inventory preclude the attribution of inventory corrections from their GOSAT inversions to specific source sec- tors. Many individual countries produce national inventories using more accurate IPCC tier 2/3 methods but these inventories are generally available only as national totals and are thus not usable for inversions, where information on spatial patterns is essential.

The need for improved, finely gridded bottom-up inventories for inverse analyses is well recognized. Wang and Bentley (2002) disaggregated the Australian national inventory to guide inversion of surface observations at Cape Grim, Tasmania. Zhao et al. (2009) disaggregated the California Air Resources Board (CARB) statewide inventory to a $0.1^{\circ} \times 0.1^{\circ}$ grid. Hiller et al. (2014) disaggregated the Swiss national inventory to a $500 \times 500 \mathrm{~m}^{2}$ grid. Maasakkers et al. (2016) developed a gridded $0.1^{\circ} \times 0.1^{\circ}$ version of the national US emission inventory produced by the EPA (Fig. 1), which shows major differences with EDGAR in terms of source patterns even though the national totals are similar.

\subsubsection{Positivity of the solution}

The standard assumption of Gaussian error PDFs for the prior estimate allows for the possibility of negative methane emissions. Although soils can be a weak sink for methane (Kirschke et al., 2013), negative emissions are generally unphysical. Small negative values may be acceptable as noise, and can be removed by averaging them with neighboring positive values. The analytical solution to the Bayesian inverse problem requires Gaussian error PDFs (Sect. 3.1), but numerical solutions do not. Adjoint-based inversions may use lognormal (Wecht et al., 2014a) or semi-exponential (Bergamaschi et al., 2013) error distributions to prevent negative solutions. Lognormal errors can be used in the analytical solution by adopting as state vector the logarithm of emissions. Miller et al. (2014) present additional approaches for imposing positivity of the solution, including (1) application of Karush-Kuhn-Tucker (KKT) conditions, and (2) MCMC methods with sampling domain restriction. These approaches will tend to bias the solution by enforcing zero values for a subset of the state vector (KKT conditions) or by artificially inflating the PDF of the prior estimate in the vicinity of zero (MCMC methods).

\subsubsection{Variability in the methane background}

Observations from the HIPPO pole-to-pole aircraft campaigns over the Pacific in 2010-2011 indicate background concentrations of tropospheric methane varying with latitude from 1750 to $1800 \mathrm{ppb}$ in the Southern Hemisphere to 1850$1900 \mathrm{ppb}$ at high northern latitudes (Wofsy, 2011). The midlatitude background varies on synoptic scales under the alternating influence of high-latitude and low-latitude air masses. This variability in background is comparable to the magnitude of concentration enhancements in methane source regions, so that accurate accounting of the global methane background and its variability is essential for regional in- 
versions. Local source inversions may be able to use regional background information upwind of the source instead (Krings et al., 2013).

Observations at remote sites from the NOAA Earth System Research Laboratory (ESRL) network (Dlugokencky et al., 2013; Andrews et al., 2014) accurately characterize the seasonal latitude-dependent background, and one can then rely on the CTM used as forward model in the inversion to resolve the synoptic variations in that background. Global inversions of satellite data have exploited the NOAA ESRL network data in different ways. Bergamaschi et al. $(2009,2013)$, Fraser et al. (2013), and Alexe et al. (2015) included the data in their inversions together with the satellite data. Cressot et al. (2014) conducted separate inversions with NOAA ESRL and satellite data, and demonstrated consistency between the two. In limited-domain inversions such as on the continental scale of North America, the background must be specified as a time- and latitude-dependent boundary condition. This has been done by Miller et al. (2013) using the NOAA ESRL data as boundary conditions, in Wecht et al. (2014a) by optimizing the boundary conditions as part of the inversion, and by Turner et al. (2015) by using results from a global inversion as boundary conditions for the continental-scale inversion.

\subsubsection{Methane sink in the troposphere}

The main sink for methane is oxidation by the $\mathrm{OH}$ radical in the troposphere, with a lifetime of 9 years constrained by global observations of methyl chloroform (MCF) (Prather et al., 2012). OH is produced photochemically and its concentration is controlled by complex chemistry that is not well represented in models (Voulgarakis et al., 2013). However, the loss of methane is sufficiently slow so that variability in $\mathrm{OH}$ concentrations affects methane concentrations only on seasonal, interannual, and interhemispheric scales (Bousquet et al., 2006). It does not affect the regional-scale gradients relevant to inverse analyses of satellite data. Global inverse analyses generally compute the methane sink by using specified global 3-D monthly fields of $\mathrm{OH}$ concentrations from an independent simulation of tropospheric oxidant chemistry that are compatible with the MCF constraint (Bergamaschi et al., 2013; Houweling et al., 2014). Cressot et al. (2014) optimized methane and MCF emissions together in their inversion, thus allowing for adjustment of $\mathrm{OH}$ concentrations within the uncertainty range allowed by MCF. Specifying $\mathrm{OH}$ concentrations is not an issue for limited-domain inversions with spatial boundary conditions because the modeling domain is then ventilated on a timescale considerably shorter than the 9-year methane lifetime. In that case, information on the methane sink is effectively incorporated in the boundary conditions.

\subsubsection{Stratospheric methane}

Inversions of satellite methane data require a proper accounting of the stratosphere. The stratosphere contributes about $5 \%$ of the total methane column in the tropics and $25 \%$ at high latitudes (Ostler et al., 2015). Methane enters the stratosphere in the tropics and is transported to high latitudes on a timescale of about 5 years. Over that time it is photochemically oxidized by $\mathrm{OH}, \mathrm{O}\left({ }^{1} \mathrm{D}\right)$, and $\mathrm{Cl}$ atoms, leading to a seasonal variation in the column mean mole fraction $\mathrm{X}_{\mathrm{CH}_{4}}$ out of phase with tropospheric methane (Saad et al., 2014). Meridional transport in the stratosphere tends to be too fast in models, so that stratospheric methane concentrations at high latitudes are overestimated (Patra et al., 2011). Not correcting for this effect in inversions can lead to a $5 \%$ overestimate of methane emissions at northern mid-latitudes and a $40 \%$ overestimate in the Arctic (Ostler et al., 2015). Quantifying emissions from boreal wetlands is severely compromised.

A number of observational data sets are available to evaluate the stratospheric methane simulation in CTMs. These include balloons (Bergamaschi et al., 2013), TCCON stratospheric retrievals (Saad et al., 2014), and satellite observations by solar occultation and in the limb (de Mazière et al., 2008; von Clarmann et al., 2009; Minschwaner and Manney, 2014). Bergamaschi et al. (2013) presented a detailed evaluation of their CTM with balloon observations as a prelude to inversion of SCIAMACHY data, and this led them to limit their inversion to the $50^{\circ} \mathrm{S}-50^{\circ} \mathrm{N}$ latitudinal range where model bias was small. Another approach is to apply a latitudinal bias correction for the difference between the CTM and the satellite data (Turner et al., 2015). Ostler et al. (2015) presented a method to correct for stratospheric methane bias in CTMs by using constraints on the age of air in the stratosphere from vertical profiles of sulfur hexafluoride $\left(\mathrm{SF}_{6}\right)$.

\subsubsection{Error characterization}

Estimation of prior and observational error covariances is crucial for inverse modeling. Observational error is the sum of instrument and CTM errors. We discussed in Sect. 2.2 the characterization of instrument error by validation with suborbital data. CTM error variance can be estimated by intercomparison of different CTMs (Patra et al., 2011) and added to the instrument error variance in quadrature. An alternative is to estimate the total observational error variance by the residual error method (Heald et al., 2004), which uses statistics of differences between the observations and the CTM simulation with prior emissions. In that method, systematic difference (bias) is assumed to be caused by error in emissions (to be corrected in the inversion), The remaining residual difference (averaging to zero) defines the total observational error, including contributions from instrument and CTM errors. This method has the merit of being consistent with the premise that the observational error is random. The CTM error variance can then be deduced by subtracting the 
instrument error variance. Application to SCIAMACHY and GOSAT shows that the instrument error tends to be dominant (Wecht et al., 2014a; Turner et al., 2015). Error correlation populating the off-diagonal terms of the observational error covariance matrix is typically specified as an $e$-folding characteristic length scale (Heald et al., 2004).

Error in the prior bottom-up emission inventory can be estimated by propagation of errors in the variables used to construct the inventory (US EPA, 2016), or by comparison of independently generated inventories such as the WETCHIMP intercomparison for wetlands (Melton et al., 2013) or regional anthropogenic inventories in the US (Maasakkers et al., 2016). Error PDFs are usually assumed to be normal or lognormal, but more skewed PDFs may better capture the occurrence of "super-emitters" (Zavala-Araiza et al., 2015). Errors may be scale-dependent, such that spatial aggregation of emission grid squares in the inversion decreases the error variance (Maasakkers et al., 2016). The prior error covariance matrix is usually taken to be diagonal, but some error correlation would in fact be expected for a given source sector. This is accounted for in the geostatistical inversion approach (Eq. 11) by assuming coherence in source patterns.

Sources completely missing from the prior bottom-up inventory pose a particular difficulty for inverse modeling, because inverse methods applied to an underconstrained problem will tend to correct emissions where the prior estimate indicates them to be. Simply increasing the error on the prior estimate is not a satisfactory approach because the inverse solution may then misplace emissions. Before conducting the inversion it is important to compare the CTM simulation using prior emissions to the observations, and diagnose whether any elevated values in the observations that are absent in the simulation could represent missing sources.

\subsection{Applications to SCIAMACHY and GOSAT data}

Most inversions of SCIAMACHY and GOSAT satellite data for atmospheric methane have been done on the global scale, estimating emissions at the resolution of the CTM used as a forward model (typically a few hundred $\mathrm{km}$ ) by applying an adjoint method (Bergamaschi et al., 2009, 2013; Spahni et al., 2011; Monteil et al., 2013; Cressot et al., 2014; Houweling et al., 2014; Alexe et al., 2015). Fraser et al. (2013) estimated monthly methane fluxes over continental-scale source regions by using an analytical method with a Kalman filter. Wecht et al. (2014a) and Turner et al. (2015) used continental-scale inversions for North America to estimate emissions at up to $50 \mathrm{~km}$ resolution in source regions through optimal selection of the state vector, with Turner et al. (2015) applying an analytical inversion to characterize errors. Fraser et al. (2014) and Pandey et al. (2015) optimized both methane and $\mathrm{CO}_{2}$ fluxes using $\mathrm{X}_{\mathrm{CH}_{4}} / \mathrm{X}_{\mathrm{CO}_{2}}$ ratios observed from GOSAT, thus avoiding the need for independent specification of $\mathrm{CO}_{2}$ concentrations in the $\mathrm{CO}_{2}$ proxy method for methane retrieval. Cressot et al. (2014) and Alexe et al. (2015) com- pared results from inversions using different SCIAMACHY and GOSAT retrievals, and found overall consistency in different regions of the world; however, Cressot et al. (2014) pointed out large errors when using the degraded post-2005 SCIAMACHY data (see Sect. 2.2).

Inversions of methane fluxes using GOSAT data show consistency with observations from NOAA ESRL surface sites, both in joint inversions (Bergamaschi et al., 2009, 2013; Fraser et al., 2013; Alexe et al., 2015) and in independent evaluations (Turner et al., 2015). GOSAT observations are sparse, with observation points separated by about $260 \mathrm{~km}$, but still provide considerably more information on methane emissions at the continental scale than the surface network observations (Fraser et al., 2013; Alexe et al., 2015). This is particularly true in the tropics, where methane emissions are large but surface observations are few (Bergamaschi et al., 2013; Cressot et al., 2014; Houweling et al., 2014).

Inversions of SCIAMACHY and GOSAT data have revealed important biases in bottom-up inventories of methane emissions. Monteil et al. (2013) and Spahni et al. (2011) find large errors in wetland emission models. Bergamaschi et al. (2013) find that 2003-2010 growth in Chinese emissions is less than estimated by EDGAR. Inversion results in the US show that EDGAR emissions in the South Central US are too low while emissions along the East Coast are too high (Wecht et al., 2014a; Alexe et al., 2015; Turner et al., 2015).

Ultimately, the application of satellite data to improve understanding of methane emissions requires that the optimized estimates from the inversions be related to specific source sectors and processes in the bottom-up inventories. SCIAMACHY observations over wetlands have been used in this manner to improve bottom-up models of wetland emissions (Bloom et al., 2010, 2012; Spahni et al., 2011). Application of satellite observations to improve anthropogenic emission inventories has so far been stymied by poor representation of emission patterns in the inventories. For example, the EDGAR underestimation in the South Central US cannot be confidently attributed to livestock or oil-gas sectors because EDGAR emission patterns for these sectors are incorrect (Maasakkers et al., 2016).

Satellite data sets for correlative variables could help relate methane observations to source sectors but this has received little attention so far. Bloom et al. (2012) combined methane data from SCIAMACHY with water height data from the GRACE satellite instrument to improve their bottom-up inventory of wetland methane emissions. Worden et al. (2012) combined measurements of methane and CO from TES to quantify methane emissions from Indonesian fires. TIR measurements of ammonia are available from the TES, IASI, and CrIS satellite instruments (Shephard et al., 2011; Van Damme et al., 2014; Shephard and Cady-Pereira, 2015) and provide a fingerprint of agricultural emissions (Zhu et al., 2013) but have yet to be exploited in combination with methane satellite data. Interpretation of the ammonia data is complicated by gas-aerosol partitioning with ammonium. In 
addition, ammonia is mainly emitted by manure and fertilizer, whereas methane is mostly emitted by enteric fermentation and the sources may not be collocated. Ethane provides a marker for oil-gas emissions but is observed from space only by solar occultation with sensitivity limited to the upper troposphere (González Abad et al., 2011). In addition, the ethane / methane emission ratio is highly variable. TROPOMI will provide data for both methane and $\mathrm{CO}$ from common SWIR retrievals. Beyond constraining the combustion source of methane, the $\mathrm{CO}$ observations could be valuable for decreasing model transport errors in joint methaneCO inversions (Wang et al., 2009).

\subsection{Potential of future satellite observations}

Future satellite instruments listed in Table 1 will have higher pixel resolution, spatial density, and temporal frequency than SCIAMACHY or GOSAT. Several studies have examined how these attributes will improve the capability of methane flux inversions. Wecht et al. (2014b) conducted an inversion of methane emissions in California at $1 / 2^{\circ} \times 2 / 3^{\circ}$ resolution using boundary layer observations from the MayJune 2010 CalNex aircraft campaign and concurrent observations from GOSAT. They then estimated the information that TROPOMI or the GEO-CAPE geostationary mission would have provided over the 2-month period through analysis of the corresponding observational error correlation matrices. Inversion of the CalNex aircraft data provided 12 independent pieces of information (DOFS) on the spatial distribution of emissions in California as compared to 1.3 for GOSAT, 11 for TROPOMI, and 26 for GEO-CAPE. TROPOMI could thus constrain emissions with a skill comparable to a dedicated statewide aircraft campaign, and a geostationary mission with hourly observations would provide much more. The study likely underestimated the capability of TROPOMI and GEO-CAPE to resolve hotspots because of the coarse $1 / 2^{\circ} \times 2 / 3^{\circ}$ resolution of the forward model. We return to this point in Sect. 4.

Bousserez et al. (2016) explored the potential of geostationary observations to constrain methane emissions on the continental scale of North America over weekly and monthly timescales. Again they used a CTM with $1 / 2^{\circ} \times 2 / 3^{\circ}$ spatial resolution as the forward model and averaged the $4 \times 4 \mathrm{~km}^{2}$ geostationary observation pixels over that coarser grid with corresponding error reduction. They considered three different configurations of geostationary instruments observing hourly in the SWIR, TIR, and SWIR + TIR (multispectral retrieval). They found that SWIR geostationary observations would effectively constrain methane emissions over the $1 / 2^{\circ} \times 2 / 3^{\circ}$ grid on a monthly timescale, while a combined SWIR + TIR instrument could deliver that information on a weekly timescale.

Bovensmann et al. (2010) examined the potential of CarbonSat to detect methane point sources by inversion of the Gaussian dispersion plume, and Rayner et al. (2014) did the same for geoCARB. We review their results in the next section.

\section{Observing requirements for regional and point sources}

Here we present a simple analysis of the potential of future satellite instruments for observing regional and point sources from space. Observation requirements are somewhat different for climate policy and for point source monitoring purposes. From a climate policy standpoint, the goal is to quantify annual mean emissions with emphasis on the regional scale and source attribution. This plays to the strength of satellites, as repeated observations of the same scene measure the temporal average with improved precision and also smooth out the temporal variability that can bias estimates from short-term field campaign data. From a point source monitoring standpoint, on the other hand, we may be most interested in detecting large leaks or venting from facilities emitting far more than would be expected on the basis of normal operations (the so-called "super-emitters"). Here the advantage of satellite data is spatial coverage, but a requirement is to have a localized and detectable signal on short timescales, with detection and localization often being more important than precise quantification.

For conceptual purposes we define detection and quantification as the ability to observe the methane enhancement $\Delta \mathrm{X}$ [ppb] from a source relative to the surrounding background. Single-scene instrument precisions $\sigma[\mathrm{ppb}]$ are taken from Table 1, and we make the optimistic assumption that precision improves with the square root of the number of observations following the central limit theorem (Kulawik et al., 2016). We define detectability as a precision of $\Delta X / 2$ and quantification as a precision of $\Delta \mathrm{X} / 5$. Only a fraction $F$ of pixels is successfully retrieved because of clouds, unsuccessful spectral fits, or other factors. The time required for detection and quantification of the source is then

$t=t_{R} \max \left[1, \frac{1}{F N} \max \left[1,\left(\frac{q \sigma}{\Delta \mathrm{X}}\right)^{2}\right]\right]$,

where $N$ is the number of observations of the source for a single satellite pass, $t_{R}$ is the time interval between passes, and $q$ takes on values of 2 for detection and 5 for quantification.

We first examine the capability of satellite instruments to quantify emissions from a large source region by taking as an example the Barnett Shale in Northeast Texas, a $300 \times 300 \mathrm{~km}^{2}$ region with about 30000 active wells as well as livestock operations and the Dallas-Fort Worth metropoli$\tan$ area. An intensive field campaign was conducted in the region in September-October 2013 to characterize individual sources (Harriss et al., 2015). Synthesis of the data by Lyon et al. (2015) gives a total emission for the region of $72 \mathrm{th}^{-1}$. Take the Barnett Shale region as a square of side 
Table 2. Nominal capability for observing regional and point sources of methane from space.

\begin{tabular}{lll}
\hline Instrument $^{\mathrm{a}}$ & $\begin{array}{l}\text { Regional source quantification } \\
\left(Q=72 \mathrm{th}^{-1} \text { over } 300 \times 300 \mathrm{~km}^{2}\right)^{\mathrm{b}}\end{array}$ & $\begin{array}{l}\text { Point source detection threshold } \\
\left(Q_{\mathrm{min}}, \mathrm{th}^{-1}\right)\end{array}$ \\
\hline SCIAMACHY & $\begin{array}{l}\text { 1-year averaging time } \\
\text { 1-year averaging time }\end{array}$ & 68 \\
GOSAT & single pass (1 day) & 4.1 \\
TROPOMI & $\mathrm{NA}^{\mathrm{d}}$ & 0.2 \\
GHGSat & 4-month averaging time & 4.0 \\
GOSAT-2 & 7-month averaging time & $\mathrm{f}$ \\
MERLIN & single pass $(5-10$ days $)$ & $\mathrm{NA}$ \\
CarbonSat & single pass $(1 \mathrm{~h})$ & 0.80 \\
GEO-CAPE, & 4.0 \\
GeoFTS & single pass $(2 \mathrm{~h})$ & $0.61 \mathrm{~g}$ \\
geoCARB & single pass $(2-8 \mathrm{~h})$ & 4.0 \\
G3E & single pass $(2 \mathrm{~h})$ & 1.3 \\
\hline
\end{tabular}

${ }^{a}$ See Table 1 for instrument specifications. ${ }^{b}$ Example of the Barnett Shale region in Northeast Texas (Lyon et al., 2015).

c Smallest point source detectable in a single observing pass. Detectability scales as $Q / U$ and is given here for a wind

speed $U=5 \mathrm{~km} \mathrm{~h}^{-1}$. d Not applicable. GHGSat has a $12 \times 12 \mathrm{~km}^{2}$ viewing domain, designed to observe point sources.

$\mathrm{e}^{\mathrm{e}}$ Assuming $5 \%$ precision. ${ }^{\mathrm{f}}$ Assuming $1.5 \%$ precision. ${ }^{\mathrm{g}}$ Assuming $0.2 \%$ precision.

$W=300 \mathrm{~km}$ ventilated by a uniform wind of speed $U$. The mean enhancement $\Delta \mathrm{X}$ relative to the upwind background is obtained by mass balance:

$\Delta \mathrm{X}=\frac{M_{\mathrm{a}}}{M_{\mathrm{CH}_{4}}} \frac{Q g}{U W p}$,

where $M_{\mathrm{a}}=0.029 \mathrm{~kg} \mathrm{~mol}^{-1}$ and $M_{\mathrm{CH}_{4}}=0.016 \mathrm{~kg} \mathrm{~mol}^{-1}$ are the molecular weights of dry air and methane, $p$ is the dry atmospheric surface pressure, and $g=9.8 \mathrm{~m} \mathrm{~s}^{-2}$ is the acceleration of gravity. Taking $U=5 \mathrm{~km} \mathrm{~h}^{-1}$ and $p=1000 \mathrm{hPa}$, and with $Q=72 \mathrm{tCH}_{4} \mathrm{~h}^{-1}$, we obtain $\Delta \mathrm{X}=8.5 \mathrm{ppb}$ or $0.47 \%$.

Table 2 summarizes the capabilities of the SWIR instruments in Table 1 to quantify such a source. GOSAT views 2-3 pixels for a $300 \times 300 \mathrm{~km}^{2}$ region on a given orbit in its routine survey mode and has a return time of 3 days. The single-retrieval precision of GOSAT is $0.7 \%$ or $13 \mathrm{ppb}$. On average $17 \%$ of GOSAT land pixels are retrieved successfully in the Parker et al. (2011) $\mathrm{CO}_{2}$ proxy retrieval $(F=0.17)$. Replacement in Eq. (12) implies that it takes about 1 year for GOSAT to effectively quantify emissions from the Barnett Shale. This explains why inverse analyses of GOSAT data retain substantial information from the prior as diagnosed by the averaging kernel matrix (Turner et al., 2015). A similar averaging time requirement applies to SCIAMACHY (2003-2005), which has denser observations but coarser precision and a smaller fraction of successful retrievals $(F=0.09)$. GOSAT- 2 with an expected singleretrieval precision of $0.4 \%$ would reduce this time to about 4 months. TROPOMI will have full daily coverage of the Barnett Shale region with about 1000 observing pixels, thus quantifying the regional emissions in a single day of observation.
Consider now the problem of detecting individual point sources through observations of the corresponding source pixels. We estimate for the different solar backscatter instruments of Table 1 the detection threshold at the scale of a satellite pixel for a single observation pass, by assuming low emissions in neighboring pixels (to characterize a local background) and clear skies (for favorable retrieval conditions). The enhancement $\Delta \mathrm{X}$ in the source pixel is given by Eq. (13) but with $W$ now representing the pixel size and with $N=1$ and $F=1$ in Eq. (12). By combining Eqs. (12) and (13) we derive the minimum source $Q_{\min }$ for single-pass detection as

$Q_{\min }=\frac{M_{\mathrm{CH}_{4}}}{M_{\mathrm{a}}} \frac{U W p q \sigma}{g}$.

Table 2 gives the detection thresholds for the different satellite instruments with $U=5 \mathrm{~km} \mathrm{~h}^{-1}$. These values can be compared to detailed point source information available for the US. Figure 8 shows the high end of the distributions of annual emissions for (1) the gridded $0.1^{\circ} \times 0.1^{\circ}$ EPA inventory of Maasakkers et al. (2016) and (2) the 6887 individual point sources reporting methane emissions to the EPA Greenhouse Gas Reporting Program (GHGRP). Reporting to the GHGRP is required for all sources in excess of $25 \mathrm{Gg} \mathrm{CO}_{2}$ equivalent $\mathrm{a}^{-1}$ (corresponding to $0.1 \mathrm{tCH}_{4} \mathrm{~h}^{-1}$ for a pure methane source). The GHGRP data include combustion sources with very low methane emissions; hence, Fig. 8 only shows the top 15 th percentile of point sources (accounting for $85 \%$ of total GHGRP methane emissions). The largest point sources in the GHGRP data with emissions in excess of $1 \mathrm{th}^{-1}$ are underground coal mines and landfills; individual point sources from oil-gas systems (compressor stations, processing plants) are smaller. Emissions from natural gas production (including wells and gathering stations) are reported to the GHGRP as basin totals instead of as point 


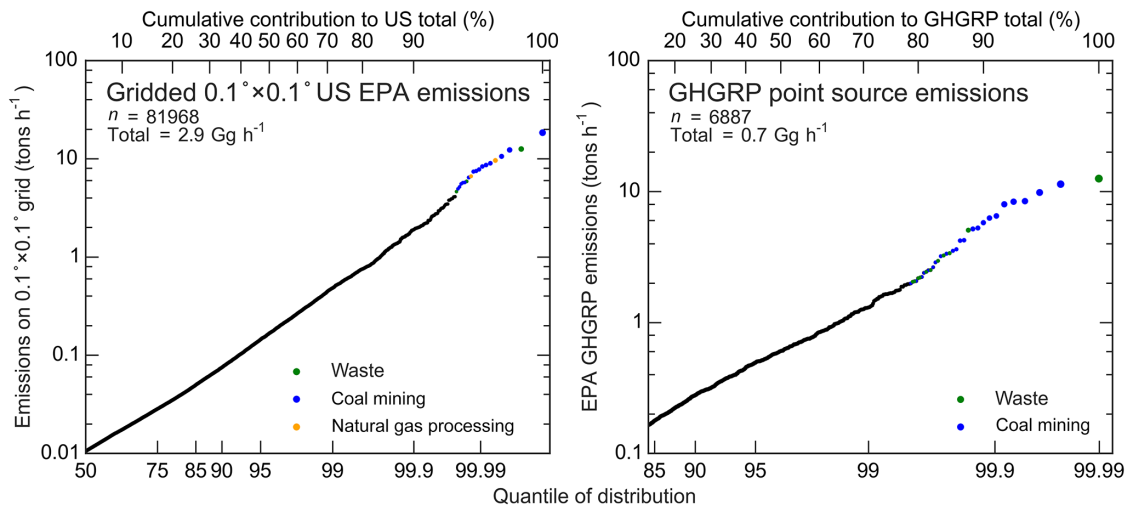

Figure 8. Cumulative frequency distribution of spatially resolved annual mean methane emissions in the contiguous US. The left panel shows the distribution of emissions at $0.1^{\circ} \times 0.1^{\circ}$ resolution in the gridded US EPA inventory for 2012 (Maasakkers et al., 2016). The right panel shows the distribution of point source emissions in the Greenhouse Gas Reporting Program (GHGRP) data for 2012. The highest sources are colored by sector. The $x$ axis is a normal cumulative probability scale such that a lognormal distribution would plot as a straight line. The cumulative relative contribution to the national total emissions is shown as the top axis. As an example of how to read these plots, the top $1 \%$ of GHGRP point source emissions (99th quantile in the right panel) includes $n=6887 / 99=69$ point sources larger than $1.2 \mathrm{th}^{-1}$ and contributes $29 \%$ of total US point source emissions in the GHGRP inventory.

sources and are thus not included in the point source distribution of Fig. 8 (but are included in the gridded emissions). Individual "super-emitters" in oil-gas fields can emit in excess of $1 \mathrm{th}^{-1}$ but this is likely on an intermittent basis (ZavalaAraiza et al., 2015; Lyon et al., 2015).

Pixel resolution of the satellite instrument can be a limiting factor for detecting individual point sources because these are often clustered on a 1-10 km scale (Lyon et al., 2015). For a satellite instrument with pixel resolution $\sim 10 \mathrm{~km}$, the frequency distribution of gridded $0.1^{\circ} \times 0.1^{\circ}\left(\approx 10 \times 10 \mathrm{~km}^{2}\right)$ emissions in Fig. 8 is more relevant than that of GHGRP point sources.

Comparison of the detection thresholds in Table 2 with the emission distributions in Fig. 8 offers insight into the capabilities of the different instruments for resolving point sources. With a detection limit of $4 \mathrm{th}^{-1}$ (for a wind of $5 \mathrm{~km} \mathrm{~h}^{-1}$ ), TROPOMI can detect in a single pass the 20 highest $0.1^{\circ} \times 0.1^{\circ}$ pixels in the gridded EPA inventory, contributing $5 \%$ of national emissions. It would not detect a typical transient "super-emitter" of $1.0 \mathrm{th}^{-1}$ in an oil-gas field in a single overpass. Because of its full daily coverage, TROPOMI can be far more effective at detecting sustained point sources and quantifying their annual emissions. For 365 successive passes (once a day) and a successful retrieval rate of $17 \%$, TROPOMI should be able to isolate individual pixel sources of $0.5 \mathrm{th}^{-1}$, representing the top $1 \%$ of $0.1^{\circ} \times 0.1^{\circ}$ grid squares in the EPA inventory and amounting to $30 \%$ of total US emissions. GOSAT-2 has a similar single-pass sensitivity to point sources as TROPOMI when observing in target mode but has much sparser coverage.

GHGSat and CarbonSat are designed for observation of point sources. If it meets its specifications of Table 1, GHGSat will have a single-pass detection threshold of
$0.24 \mathrm{th}^{-1}$ (for a wind of $5 \mathrm{~km} \mathrm{~h}^{-1}$ ). This will detect $700 \mathrm{of}$ the GHGRP point sources in Fig. 8, corresponding to $80 \%$ of the national total in the GHGRP point source inventory. A single GHGSat instrument will have a return time of 2 weeks, limiting its ability to detect transient "super-emitters", but long-term plans are for a fleet of instruments on microsatellites.

Bovensmann et al. (2010) give a CarbonSat detection threshold of $0.24 \mathrm{th}^{-1}$ for $U=5 \mathrm{~km} \mathrm{~h}^{-1}$, based on inversion of data from a transported Gaussian plume. We find a threshold of $0.8 \mathrm{th}^{-1}$ for single-pixel detection. Mapping of the methane plume in downwind pixels offers additional opportunity for detecting and quantifying a point source as long as there is no overlap with other sources and some model of plume transport is applied. Bovensmann et al. (2010) did not include transport error in their analysis which may have led to overoptimistic results. With $2 \times 2 \mathrm{~km}^{2}$ pixel resolution, CarbonSat would be limited in its ability to resolve the structure of individual methane plumes since airborne mapping shows plumes to be smaller in scale even for large point sources (Krings et al., 2013; Thorpe et al., 2016; Frankenberg et al., 2016). The $0.05 \times 0.05 \mathrm{~km}^{2}$ resolution of GHGSat, with imaging over a $12 \times 12 \mathrm{~km}^{2}$ grid, has better potential for resolving the plume structure. A complication in remote sensing of plumes with sub-kilometer pixels is that one may not assume that the incident and reflected solar rays (Fig. 2) sample the same boundary layer methane column. The air mass factor calculation must trace the propagation of the incident and reflected solar rays through the plume, taking into account the solar azimuth and zenith angles as well as the altitude of the plume.

Several approaches have been used to exploit downwind plume information for inferring point source emissions, in- 
cluding (1) inverse modeling with source strength and dispersion parameters as state variables (Krings et al., 2011, 2013), (2) integrating the flux over the plume cross-section normal to wind direction (Conley et al., 2016), and (3) summing the above-background mass in all plume pixels and relating this integrated mass enhancement to emission by using a relationship from known sources or a plume dispersion model (Frankenberg et al., 2016). Choice of the best approach may depend on the level of meteorological information available and the ability of the instrument to map the observed plume structure, which in turn depends on the pixel size, the measurement noise, the ability to define the local background, and the complexity of the flow including the effect of wind shear (Rayner et al., 2014).

Geostationary observations can in principle achieve high precision together with fine pixel resolution because the viewing geometry allows much longer observation times. But there is competing demand for spatial coverage. Currently proposed geostationary missions (Table 1 ) expect to achieve $0.2-1 \%$ precision for pixels $2-5 \mathrm{~km}$ in size, limited in part by their stated mission objectives of observing continentalscale domains several times a day. With this implementation and the assumptions above, a regional source such as the Barnett Shale is strongly constrained on a single-pass basis but the capability to detect transient point sources is limited (Table 2). Point sources could be detected more effectively from geostationary orbit by adopting longer viewing times per pixel and/or using finer pixels. This could be achieved by limiting the domain of observation or by using "special observations" where the instrument is maneuvered to stare at specific points of interest. For example, detection of an anomaly in emissions, either from the satellite or from suborbital observations, could motivate targeted observation by the satellite to localize and quantify the anomaly. A schedule of alternate days for continental-scale mapping and for special observations could be effective in quantifying emissions at the national and regional scales while also providing fast detection and quantification of point sources.

Airborne remote sensing offers another way to observe methane emissions from point sources, using the same techniques as satellite remote sensing but with much higher spatial resolution. The methane airborne mapper (MAMAP) (Krings et al., 2011) retrieves methane in the SWIR at $1.6 \mu \mathrm{m}$, similar to SCIAMACHY, but currently lacks imaging capabilities. Imaging spectrometers initially designed for surface remote sensing have been shown to detect methane plumes with horizontal resolution as fine as $1 \mathrm{~m}$ either in the SWIR using the strong $2.3 \mu \mathrm{m}$ band (Roberts et al., 2010; Thorpe et al., 2016) or in the TIR (Tratt et al., 2014; Hulley et al., 2016). These imaging spectrometers such as AVIRISNG (SWIR) and MAKO or HyTES (TIR) have much coarser spectral resolution than MAMAP or current satellite instruments (e.g., $5 \mathrm{~nm}$ for AVIRIS-NG). However, at this fine spatial resolution, concentration enhancements over point sources are much higher and can be discerned down to a detection threshold of only $2 \mathrm{~kg} \mathrm{~h}^{-1}$ (Thorpe et al., 2016). A major advantage is that the fine structure of the plume shape can be observed, allowing for localized source attribution (Thompson et al., 2015; Thorpe et al., 2016).

\section{Conclusions and recommendations}

We have reviewed the capabilities for observing atmospheric methane from space and their utility for improving knowledge of methane emissions through inverse analyses. Observations in the shortwave infrared (SWIR) are of most interest for quantifying emissions because they are sensitive to the full atmospheric column down to the surface. Retrievals combining the SWIR and the thermal infrared (TIR) would isolate the lower tropospheric contribution to methane and thus reduce uncertainties in accounting for the free tropospheric background and the stratosphere.

Current SWIR observations from the GOSAT satellite are of high quality but sparse. Through inverse analyses and annual averaging they can quantify emissions in source regions on a $100-1000 \mathrm{~km}$ scale. The TROPOMI instrument, to be launched in 2017 , will be able to map emissions daily on that scale and will also have the capability to detect and quantify large point sources. As such it will significantly enhance the value of satellite measurements to serve the needs of climate policy. The GHGSat instrument launched in 2016 with $50 \times 50 \mathrm{~m}^{2}$ pixel resolution over $12 \times 12 \mathrm{~km}^{2}$ viewing domains will effectively detect methane point sources if it meets its specification of $1-5 \%$ precision. Arctic sources of methane are difficult to observe from space because of limited solar radiation and because of uncertainty in accounting for stratospheric methane. Future lidar observations from MERLIN offer a unique resource for observing the Arctic under dark conditions.

The ultimate goal of top-down inverse analyses of atmospheric observations is to guide the improvement of bottomup emission inventories relating emissions to the underlying processes. There is the opportunity to gain considerable synergy between top-down and bottom-up approaches by using high-quality bottom-up inventories as prior estimates in inversions, and then using inversion results to improve the inventories. Exploiting this synergy requires the construction of finely gridded, sector-resolved bottom-up inventories including error estimates.

Geostationary observations (still at the proposal stage) hold considerable potential for monitoring methane emissions from space. The geostationary orbit allows sustained staring at individual pixels, providing a unique opportunity to infer emissions with both high spatial and temporal resolution on national scales. This also enables the characterization of diurnally varying sources such as from wetlands (Mikkela et al., 1995) and manure (Wood et al., 2013), where LEO sun-synchronous observations at a single time of day might provide a biased estimate. Current geostationary mis- 
sion proposals emphasize hourly mapping of emissions at the continental scale. This limits their pixel resolution and their precision. It is not clear that high-frequency continental-scale mapping from geostationary orbit is of much value if sufficient information is already available from a LEO instrument such as TROPOMI. It may be more effective for a geostationary mission to focus on selective observation of point sources and source regions, enabling finer pixel resolution and longer viewing times to resolve emissions at local scale including transient sources.

More work needs to be done in exploiting correlative observations to increase the value of methane satellite data, but the task is difficult because of the uniqueness of methane sources. Observations of ammonia from space are becoming mature and provide a marker of agricultural operations, though the sources of ammonia (fertilizer, manure) only partly overlap with the sources of methane (enteric fermentation, manure). Joint observations of methane and $\mathrm{CO}$, as from TROPOMI, may help to reduce model transport error in inversions through methane-CO error correlations. Satellite mapping of surface properties can provide important correlative information, as already demonstrated for wetlands. Satellite data for soil moisture, gas flaring, and imagery of point sources could be integrated with available methane data to more effectively constrain methane emissions.

Suborbital observations of methane from aircraft and from the ground are essential partners of satellite observation. Suborbital observations have a unique capability for correlative measurements such as methane isotopes and ethane that can provide additional constraints in inversions. They can confirm methane anomalies detected from space, and pinpoint sources with far greater accuracy (down to the device scale) than is achievable from space. Suborbital platforms are also essential for continual validation of the satellite data. The prospect of improving satellite observations in the near future calls for the construction of a comprehensive atmospheric methane observing system to monitor emissions from global to local scales through coordination with improved suborbital observations, bottom-up inventories, and atmospheric transport models.

\section{Data availability}

The gridded US methane inventory of Maasakkers et al. (2016) used to produce Fig. 8 is available at https://www. epa.gov/ghgemissions/gridded-2012-methane-emissions.

Acknowledgements. This work was funded by the NASA Carbon Monitoring System, by the NASA GEO-CAPE Atmospheric Sciences Working Group, by the ExxonMobil Upstream Research Company, and by the US DOE Advanced Research Projects Agency - Energy. Kelly Chance acknowledges funding from the Smithsonian Astrophysical Observatory. We thank Helen Worden for pointing out an error in the original submitted paper.
Edited by: B. N. Duncan

Reviewed by: two anonymous referees

\section{References}

Alexe, M., Bergamaschi, P., Segers, A., Detmers, R., Butz, A., Hasekamp, O., Guerlet, S., Parker, R., Boesch, H., Frankenberg, C., Scheepmaker, R. A., Dlugokencky, E., Sweeney, C., Wofsy, S. C., and Kort, E. A.: Inverse modelling of $\mathrm{CH}_{4}$ emissions for 2010-2011 using different satellite retrieval products from GOSAT and SCIAMACHY, Atmos. Chem. Phys., 15, 113-133, doi:10.5194/acp-15-113-2015, 2015.

Alvarado, M. J., Payne, V. H., Cady-Pereira, K. E., Hegarty, J. D., Kulawik, S. S., Wecht, K. J., Worden, J. R., Pittman, J. V., and Wofsy, S. C.: Impacts of updated spectroscopy on thermal infrared retrievals of methane evaluated with HIPPO data, Atmos. Meas. Tech., 8, 965-985, doi:10.5194/amt-8-965-2015, 2015.

Anderson, G., Clough, S., Kneizys, F., Chetwynd, J., and Shettle, E.: AFGL atmospheric constituent profiles $(0-120 \mathrm{~km})$, Tech. Rep. AFGL-TR-86-0110, Air Force Geophys. Lab., Hanscom Air Force Base, Bedford, Mass., 1986.

Andrews, A. E., Kofler, J. D., Trudeau, M. E., Williams, J. C., Neff, D. H., Masarie, K. A., Chao, D. Y., Kitzis, D. R., Novelli, P C., Zhao, C. L., Dlugokencky, E. J., Lang, P. M., Crotwell, M. J., Fischer, M. L., Parker, M. J., Lee, J. T., Baumann, D. D., Desai, A. R., Stanier, C. O., De Wekker, S. F. J., Wolfe, D. E., Munger, J. W., and Tans, P. P.: $\mathrm{CO}_{2}, \mathrm{CO}$, and $\mathrm{CH}_{4}$ measurements from tall towers in the NOAA Earth System Research Laboratory's Global Greenhouse Gas Reference Network: instrumentation, uncertainty analysis, and recommendations for future high-accuracy greenhouse gas monitoring efforts, Atmos. Meas. Tech., 7, 647-687, doi:10.5194/amt-7-647-2014, 2014.

Benmergui, J., Andrews, A., Thoning, K., Miller, S., Trudeau, M., Mountain, M., Nehrkorn, T., Dlugokencky, E., Masarie, K., Worthy, D., Sweeney, C., Bruhwiler, L., Desai, A., Fischer, M. L., and Wofsy, S. C.: Integrating diverse observations of North American $\mathrm{CH}_{4}$ into flux inversions in CarbonTrackerLagrange- $\mathrm{CH}_{4}$, presented at the Fall 2015 meeting of the American Geophysical Union, San Francisco, California, 2015.

Bergamaschi, P., Krol, M., Dentener, F., Vermeulen, A., Meinhardt, F., Graul, R., Ramonet, M., Peters, W., and Dlugokencky, E. J.: Inverse modelling of national and European $\mathrm{CH}_{4}$ emissions using the atmospheric zoom model TM5, Atmos. Chem. Phys., 5, 2431-2460, doi:10.5194/acp-5-2431-2005, 2005.

Bergamaschi, P., Frankenberg, C., Meirink, J. F., Krol, M., Dentener, F., Wagner, T., Platt, U., Kaplan, J. O., Körner, S., Heimann, M., Dlugokencky, E. J., and Goede, A.: Satellite chartography of atmospheric $\mathrm{CH}_{4}$ from SCIAMACHY on board ENVISAT: 2. Evaluation based on inverse model simulations, J. Geophys. Res.-Atmos., 112, D02304, doi:10.1029/2006JD007268, 2007.

Bergamaschi, P., Frankenberg, C., Meirink, J. F., Krol, M., Villani, M. G., Houweling, S., Dentener, F., Dlugokencky, E. J., Miller, J. B., Gatti, L. V., Engel, A., and Levin, I.: Inverse modeling of global and regional $\mathrm{CH}_{4}$ emissions using SCIAMACHY satellite retrievals, J. Geophys. Res., 114, D22301, doi:10.1029/2009JD012287, 2009. 
Bergamaschi, P., Houweling, S., Segers, A., Krol, M., Frankenberg, C., Scheepmaker, R. A., Dlugokencky, E., Wofsy, S. C., Kort, E. A., Sweeney, C., Schuck, T., Brenninkmeijer, C., Chen, H., Beck, V., and Gerbig, C.: Atmospheric $\mathrm{CH}_{4}$ in the first decade of the 21st century: Inverse modeling analysis using SCIAMACHY satellite retrievals and NOAA surface measurements, J. Geophys. Res.-Atmos., 118, 7350-7369, 2013.

Bloom, A. A., Palmer, P. I., Fraser, A., Reay, D. S., and Frankenberg, C.: Large-scale controls of methanogenesis inferred from methane and gravity spaceborne data, Science, 327, 322-325, doi:10.1126/Science.1175176, 2010.

Bloom, A. A., Palmer, P. I., Fraser, A., and Reay, D. S.: Seasonal variability of tropical wetland $\mathrm{CH}_{4}$ emissions: the role of the methanogen-available carbon pool, Biogeosciences, 9, 28212830, doi:10.5194/bg-9-2821-2012, 2012.

Bloom, A. A., Bowman, K., Lee, M., Turner, A. J., Schroeder, R., Worden, J. R., Weidner, R., McDonald, K. C., and Jacob, D. J.: A global wetland methane emissions and uncertainty dataset for atmospheric chemical transport models, Geosci. Model Dev. Discuss., doi:10.5194/gmd-2016-224, in review, 2016.

Bousquet, P., Ciais, P., Miller, J. B., Dlugokencky, E. J., Hauglustaine, D. A., Prigent, C., Van der Werf, G. R., Peylin, P., Brunke, E.-G., Carouge, C., Langenfelds, R. L., Lathiere, J., Papa, F., Ramonet, M., Schmidt, M., Steele, L. P., Tyler, S. C., and White, J.: Contribution of anthropogenic and natural sources to atmospheric methane variability, Nature, 443, 439-443, 2006.

Bousquet, P., Ringeval, B., Pison, I., Dlugokencky, E. J., Brunke, E.G., Carouge, C., Chevallier, F., Fortems-Cheiney, A., Frankenberg, C., Hauglustaine, D. A., Krummel, P. B., Langenfelds, R. L., Ramonet, M., Schmidt, M., Steele, L. P., Szopa, S., Yver, C., Viovy, N., and Ciais, P.: Source attribution of the changes in atmospheric methane for 2006-2008, Atmos. Chem. Phys., 11, 3689-3700, doi:10.5194/acp-11-3689-2011, 2011.

Bousserez, N., Henze, D. K., Perkins, A., Bowman, K. W., Lee, M., Liu, J., Deng, F., and Jones, D. B. A.: Improved analysiserror covariance matrix for high-dimensional variational inversions: application to source estimation using a 3D atmospheric transport model, Q. J. Roy. Meteor. Soc., 141, 1906-1921, doi:10.1002/qj.2495, 2015.

Bousserez, N., Henze, D. K., Rooney, B., Perkins, A., Wecht, K. J., Turner, A. J., Natraj, V., and Worden, J. R.: Constraints on methane emissions in North America from future geostationary remote-sensing measurements, Atmos. Chem. Phys., 16, 61756190, doi:10.5194/acp-16-6175-2016, 2016.

Bovensmann, H., Buchwitz, M., Burrows, J. P., Reuter, M., Krings, T., Gerilowski, K., Schneising, O., Heymann, J., Tretner, A., and Erzinger, J.: A remote sensing technique for global monitoring of power plant $\mathrm{CO}_{2}$ emissions from space and related applications, Atmos. Meas. Tech., 3, 781-811, doi:10.5194/amt-3-781-2010, 2010.

Brakeboer, B. N. A.: Development of the structural and thermal control subsystems for an Earth observation microsatellite and its payload, MSc Thesis, University of Toronto, 2015.

Brandt, A. R., Heath, G. A., Kort, E. A., O’Sullivan, F., Petron, G., Jordaan, S. M., Tans, P., Wilcox, J., Gopstein, A. M., Arent, D., Wofsy, S., Brown, N. J., Bradley, R., Stucky, G. D., Eardley, D., and Harriss, R.: Methane leaks from North American gas systems, Science, 343, 733-735, 2014.
Bruhwiler, L., Dlugokencky, E., Masarie, K., Ishizawa, M., Andrews, A., Miller, J., Sweeney, C., Tans, P., and Worthy, D.: CarbonTracker-CH4: an assimilation system for estimating emissions of atmospheric methane, Atmos. Chem. Phys., 14, 82698293, doi:10.5194/acp-14-8269-2014, 2014.

Buchwitz, M., Reuter, M., Bovensmann, H., Pillai, D., Heymann, J., Schneising, O., Rozanov, V., Krings, T., Burrows, J. P., Boesch, H., Gerbig, C., Meijer, Y., and Löscher, A.: Carbon Monitoring Satellite (CarbonSat): assessment of atmospheric $\mathrm{CO}_{2}$ and $\mathrm{CH}_{4}$ retrieval errors by error parameterization, Atmos. Meas. Tech., 6, 3477-3500, doi:10.5194/amt-6-3477-2013, 2013.

Buchwitz, M., Reuter, M., Schneising, O., Boesch, H., Guerlet, S., Dils, B., Aben, I., Armante, R., Bergamaschi, P., Blumenstock, T., Bovensmann, H., Brunner, D., Buchmann, B., Burrows, J., Butz, A., Chédin, A., Chevallier, F., Crevoisier, C., Deutscher, N., Frankenberg, C., Hase, F., Hasekamp, O., Heymann, J., Kaminski, T., Laeng, A., Lichtenberg, G., Mazière, M. D., Noël, S., Notholt, J., Orphal, J., Popp, C., Parker, R., Scholze, M., Sussmann, R., Stiller, G., Warneke, T., Zehner, C., Bril, A., Crisp, D., Griffith, D., Kuze, A., O'Dell, C., Oshchepkov, S., Sherlock, V., Suto, H., Wennberg, P., Wunch, D., Yokota, T., and Yoshida, Y.: The Greenhouse Gas Climate Change Initiative (GHG-CCI): Comparison and quality assessment of nearsurface-sensitive satellite-derived $\mathrm{CO}_{2}$ and $\mathrm{CH}_{4}$ global data sets, Remote Sens. Environ., 162, 344-362, 2015.

Buchwitz, M., Schneising, O., Reuter, M., Heymann, J., Krautwurst, S., Bovensmann, H., Burrows, J. P., Boesch, H., Parker, R. J., Detmers, R. G., Hasekamp, O. P., Aben, I., Butz, A., and Frankenberg, C.: Satellite-derived methane hotspot emission estimates using a fast data-driven method, Atmos. Chem. Phys. Discuss., doi:10.5194/acp-2016-755, in review, 2016.

Bui-Thanh, T., Burstedde, C., Ghattas, O., Martin, J., Stadler, G., and Wilcox, L. C.: Extreme-scale UQ for Bayesian inverse problems governed by PDEs, in: IEEE International Conference for High Performance Computing, Networking, Storage and Analysis, Salt Lake City, Utah, November 2012.

Butz, A., Hasekamp, O. P., Frankenberg, C., and Aben, I.: Retrievals of atmospheric $\mathrm{CO}_{2}$ from simulated space-borne measurements of backscattered near-infrared sunlight: accounting for aerosol effects, Appl. Optics, 48, 3322-3336, 2010.

Butz, A., Galli, A., Hasekamp, O., Landgraf, J., Tol, P., and Aben, I.: TROPOMI aboard Precursor Sentinel-5 Precursor: Prospective performance of $\mathrm{CH}_{4}$ retrievals for aerosol and cirrus loaded atmospheres, Remote Sens. Environ., 120, 267-276, 2012.

Butz, A., Orphal, J., Checa-Garcia, R., Friedl-Vallon, F., von Clarmann, T., Bovensmann, H., Hasekamp, O., Landgraf, J., Knigge, T., Weise, D., Sqalli-Houssini, O., and Kemper, D.: Geostationary Emission Explorer for Europe (G3E): mission concept and initial performance assessment, Atmos. Meas. Tech., 8, 47194734, doi:10.5194/amt-8-4719-2015, 2015.

Clerbaux, C., Hadji-Lazaro, J., Turquety, S., Mégie, G., and Coheur, P.-F.: Trace gas measurements from infrared satellite for chemistry and climate applications, Atmos. Chem. Phys., 3, 14951508, doi:10.5194/acp-3-1495-2003, 2003.

Conley, S., Franco, G., Faloona, I., Blake, D. R., Peischl, J., and Ryerson, T. B.: Methane emissions from the 2015 Aliso Canyon blowout in Los Angeles, CA, Science, 351, 1317-1321, 2016.

Cressot, C., Chevallier, F., Bousquet, P., Crevoisier, C., Dlugokencky, E. J., Fortems-Cheiney, A., Frankenberg, C., Parker, R., 
Pison, I., Scheepmaker, R. A., Montzka, S. A., Krummel, P. B., Steele, L. P., and Langenfelds, R. L.: On the consistency between global and regional methane emissions inferred from SCIAMACHY, TANSO-FTS, IASI and surface measurements, Atmos. Chem. Phys., 14, 577-592, doi:10.5194/acp-14-577-2014, 2014. Crevoisier, C., Nobileau, D., Armante, R., Crépeau, L., Machida, T., Sawa, Y., Matsueda, H., Schuck, T., Thonat, T., Pernin, J., Scott, N. A., and Chédin, A.: The 2007-2011 evolution of tropical methane in the mid-troposphere as seen from space by MetOpA/IASI, Atmos. Chem. Phys., 13, 4279-4289, doi:10.5194/acp13-4279-2013, 2013.

De Mazière, M., Vigouroux, C., Bernath, P. F., Baron, P., Blumenstock, T., Boone, C., Brogniez, C., Catoire, V., Coffey, M., Duchatelet, P., Griffith, D., Hannigan, J., Kasai, Y., Kramer, I., Jones, N., Mahieu, E., Manney, G. L., Piccolo, C., Randall, C., Robert, C., Senten, C., Strong, K., Taylor, J., Tétard, C., Walker, K. A., and Wood, S.: Validation of ACE-FTS v2.2 methane profiles from the upper troposphere to the lower mesosphere, Atmos. Chem. Phys., 8, 2421-2435, doi:10.5194/acp-8-2421-2008, 2008

Dils, B., Buchwitz, M., Reuter, M., Schneising, O., Boesch, H., Parker, R., Guerlet, S., Aben, I., Blumenstock, T., Burrows, J. P., Butz, A., Deutscher, N. M., Frankenberg, C., Hase, F., Hasekamp, O. P., Heymann, J., De Mazière, M., Notholt, J., Sussmann, R., Warneke, T., Griffith, D., Sherlock, V., and Wunch, D.: The Greenhouse Gas Climate Change Initiative (GHG-CCI): comparative validation of GHG-CCI SCIAMACHY/ENVISAT and TANSO-FTS/GOSAT $\mathrm{CO}_{2}$ and $\mathrm{CH}_{4}$ retrieval algorithm products with measurements from the TCCON, Atmos. Meas. Tech., 7, 1723-1744, doi:10.5194/amt-7-1723-2014, 2014.

Dlugokencky, E. J., Nisbet, E. G., Fisher, R., and Lowry, D.: Global atmospheric methane: budget, changes and dangers, Philos. T. R. Soc. A, 369, 2058-2072, 2011

Dlugokencky, E., Lang, P. M., Crotwell, A. M., Masarie, K. A., and Crotwell, M. J.: Atmospheric methane dry-air mole fractions from the NOAA ESRL carbon cycle cooperative global air sampling network: 1988-2012, version: 2013-06-18, available at: ftp: //aftp.cmdl.noaa.gov/data/greenhouse_gases/ch4/flask (last access: 17 November 2016), 2013.

European Commission: Joint Research Centre, and Netherlands Environmental Assessment Agency, Emission database for global atmospheric research (EDGAR), available at: http://edgar.jrc.ec. europa.eu (last access: 16 November 2016), Release version 4.2, 2011

Fishman, J. L., Iraci, L. T., Al-Saadi, J., Chance, K., Chavez, F., Chin, M., Coble, P., Davis, C., DiGiacomo, P. M., Edwards, D., Eldering, A., Goes, J., Herman, J., Hu, C., Jacob, D. J., Jordan, C., Kawa, S. R., Key, R., Liu, X., Lohrenz, S., Mannino, A., Natraj, V., Neil, D., Neu, J., Newchurch, M., Pickering, K., Salisbury, J., Sosik, H., Subramaniam, A., Tzortziou, M.,Wang, J., and Wang, M.: The United States' next generation of atmospheric composition and coastal ecosystem measurements: NASA's Geostationary Coastal and Air Pollution Events (GEO-CAPE) Mission, BAMS, doi:10.1175/BAMS-D-11-00201.1, 2012.

Frankenberg, C., Platt, U., and Wagner, T.: Iterative maximum a posteriori (IMAP)-DOAS for retrieval of strongly absorbing trace gases: Model studies for $\mathrm{CH} 4$ and $\mathrm{CO}_{2}$ retrieval from near infrared spectra of SCIAMACHY onboard ENVISAT, Atmos. Chem. Phys., 5, 9-22, doi:10.5194/acp-5-9-2005, 2005.
Frankenberg, C., Meirink, J. F., Bergamaschi, P., Goede, A P. H., Heimann, M., Körner, S., Platt, U., van Weele, M., and Wagner, T.: Satellite chartography of atmospheric methane from SCIAMACHY on board ENVISAT: Analysis of the years 2003 and 2004, J. Geophys. Res., 111, D07303, doi:10.1029/2005JD006235, 2006.

Frankenberg, C., Aben, I., Bergamaschi, P., Dlugokencky, E. J., van Hees, R., Houweling, S., van der Meer, P., Snel, R., and Tol, P.: Global column averaged methane mixing ratios from 2003 to 2009 as derived from SCIAMACHY: Trends and variability, J. Geophys. Res., 116, D04302, doi:10.1029/2010JD014849, 2011.

Frankenberg, C., Thorpe, A. K., Thompson, D. R., Hulley, G., Kort, E. A., Vance, N., Borchardt, J., Krings, T., Gerilowski, K., Sweeney, C., Conley, S., Bue, B. D., Aubrey, A. D., Hook, S., and Green, R. O.: Airborne methane remote measurements reveal heavy-tail flux distribution in the Four Corners region, P. Natl. Acad. Sci. USA, 113, 9734-9739, 2016.

Fraser, A., Palmer, P. I., Feng, L., Boesch, H., Cogan, A., Parker, R., Dlugokencky, E. J., Fraser, P. J., Krummel, P. B., Langenfelds, R. L., O’Doherty, S., Prinn, R. G., Steele, L. P., van der Schoot, M., and Weiss, R. F.: Estimating regional methane surface fluxes: the relative importance of surface and GOSAT mole fraction measurements, Atmos. Chem. Phys., 13, 5697-5713, doi:10.5194/acp-13-5697-2013, 2013.

Fraser, A., Palmer, P. I., Feng, L., Bösch, H., Parker, R., Dlugokencky, E. J., Krummel, P. B., and Langenfelds, R. L.: Estimating regional fluxes of $\mathrm{CO}_{2}$ and $\mathrm{CH}_{4}$ using space-borne observations of $\mathrm{XCH}_{4}: \mathrm{XCO}_{2}$, Atmos. Chem. Phys., 14, 12883-12895, doi:10.5194/acp-14-12883-2014, 2014.

Gambacorta, A., Barnet, C., Smith, N., Pierce, B., Smith, J., Spackman, R., and Goldberg, M.: The NPP and J1 NOAA Unique Combined Atmospheric Processing System (NUCAPS) for atmospheric thermal sounding: recent algorithm enhancements tailored to near real time users applications, presented at the American Geophysical Union Fall 2016 meeting, San Francisco, California, 2016.

Ganesan, A. L., Rigby, M., Zammit-Mangion, A., Manning, A. J., Prinn, R. G., Fraser, P. J., Harth, C. M., Kim, K.-R., Krummel, P. B., Li, S., Mühle, J., O’Doherty, S. J., Park, S., Salameh, P. K., Steele, L. P., and Weiss, R. F.: Characterization of uncertainties in atmospheric trace gas inversions using hierarchical Bayesian methods, Atmos. Chem. Phys., 14, 3855-3864, doi:10.5194/acp14-3855-2014, 2014.

Ganesan, A. L., Manning, A. J., Grant, A., Young, D., Oram, D. E., Sturges, W. T., Moncrieff, J. B., and O'Doherty, S.: Quantifying methane and nitrous oxide emissions from the UK and Ireland using a national-scale monitoring network, Atmos. Chem. Phys., 15, 6393-6406, doi:10.5194/acp-15-6393-2015, 2015.

Gloudemans, A. M. S., Schrijver, H., Hasekamp, O. P., and Aben, I.: Error analysis for $\mathrm{CO}$ and $\mathrm{CH}_{4}$ total column retrievals from SCIAMACHY $2.3 \mu \mathrm{m}$ spectra, Atmos. Chem. Phys., 8, 39994017, doi:10.5194/acp-8-3999-2008, 2008.

Glumb, R., Davis, G., and Lietzke, C.: The TANSO-FTS-2 instrument for the GOSAT-2 Greenhouse Gas Monitoring Mission, IEEE International Symposium on Geoscience and Remote Sensing IGARSS, 1238-1240, 2014.

González Abad, G., Allen, N. D. C., Bernath, P. F., Boone, C. D., McLeod, S. D., Manney, G. L., Toon, G. C., Carouge, C., Wang, Y., Wu, S., Barkley, M. P., Palmer, P. I., Xiao, Y., and Fu, T. 
M.: Ethane, ethyne and carbon monoxide concentrations in the upper troposphere and lower stratosphere from ACE and GEOSChem: a comparison study, Atmos. Chem. Phys., 11, 9927-9941, doi:10.5194/acp-11-9927-2011, 2011.

Harriss, R. C., Alvarez, R. A., Lyon, D., Zavala-Araiza, D., Nelson, D., and Hamburg, S. P.: Using Multi-Scale Measurements to Improve Methane Emission Estimates from Oil and Gas Operations in the Barnett Shale Region, Texas, Environ. Sci. Technol., 49, 7524-7526, 2015.

Hartmann, D. L., Klein Tank, A. M. G., Rusticucci, M., Alexander, I. V., Brönnimann, S., Charabi, Y., Dentener, F. J., Dlugokencky, E. J., Easterling, D. R., Kaplan, A., Soden, B. J., Thorne, P. W., Wild, M., and Zhai, P. M.: Observations: atmosphere and surface, in: Climate Change 2013: The Physical Science Basis, Contribution of Working Group I to the Fifth Assessment Report of the Intergovernmental Panel on Climate Change, edited by: Stocker, T. F., Qin, D., Plattner, G.-K., Tignor, M., Allen, S. K., Boschung, J., Nauels, A., Xia, Y., Bex, V., and Midgley, P. M., Cambridge University Press, Cambridge, UK and New York, NY, USA, 2013.

Heald, C., Jacob, D., Jones, D., Palmer, P., Logan, J., Streets, D., Sachse, G., Gille, J., Hoffman, R., and Nehrkorn, T.: Comparative inverse analysis of satellite (MOPITT) and aircraft (TRACEP) observations to estimate Asian sources of carbon monoxide, J. Geophys. Res., 109, D23306, doi:10.1029/2004jd005185, 2004.

Henne, S., Brunner, D., Oney, B., Leuenberger, M., Eugster, W., Bamberger, I., Meinhardt, F., Steinbacher, M., and Emmenegger, L.: Validation of the Swiss methane emission inventory by atmospheric observations and inverse modelling, Atmos. Chem. Phys., 16, 3683-3710, doi:10.5194/acp-16-3683-2016, 2016.

Henze, D. K., Hakami, A., and Seinfeld, J. H.: Development of the adjoint of GEOS-Chem, Atmos. Chem. Phys., 7, 2413-2433, doi:10.5194/acp-7-2413-2007, 2007.

Herbin, H., Labonnote, L. C., and Dubuisson, P.: Multispectral information from TANSO-FTS instrument - Part 1: Application to greenhouse gases $\left(\mathrm{CO}_{2}\right.$ and $\left.\mathrm{CH}_{4}\right)$ in clear sky conditions, Atmos. Meas. Tech., 6, 3301-3311, doi:10.5194/amt-6-3301-2013, 2013.

Hiller, R. V., Bretscher, D., DelSontro, T., Diem, T., Eugster, W., Henneberger, R., Hobi, S., Hodson, E., Imer, D., Kreuzer, M., Künzle, T., Merbold, L., Niklaus, P. A., Rihm, B., Schellenberger, A., Schroth, M. H., Schubert, C. J., Siegrist, H., Stieger, J., Buchmann, N., and Brunner, D.: Anthropogenic and natural methane fluxes in Switzerland synthesized within a spatially explicit inventory, Biogeosciences, 11, 1941-1959, doi:10.5194/bg-11-1941-2014, 2014.

Houweling, S., Krol, M., Bergamaschi, P., Frankenberg, C., Dlugokencky, E. J., Morino, I., Notholt, J., Sherlock, V., Wunch, D., Beck, V., Gerbig, C., Chen, H., Kort, E. A., Röckmann, T., and Aben, I.: A multi-year methane inversion using SCIAMACHY, accounting for systematic errors using TCCON measurements, Atmos. Chem. Phys., 14, 3991-4012, doi:10.5194/acp-14-39912014, 2014.

Hulley, G. C., Duren, R. M., Hopkins, F. M., Hook, S. J., Vance, N., Guillevic, P., Johnson, W. R., Eng, B. T., Mihaly, J. M., Jovanovic, V. M., Chazanoff, S. L., Staniszewski, Z. K., Kuai, L., Worden, J., Frankenberg, C., Rivera, G., Aubrey, A. D., Miller, C. E., Malakar, N. K., Sánchez Tomás, J. M., and Holmes, K. T.: High spatial resolution imaging of methane and other trace gases with the airborne Hyperspectral Thermal Emission Spectrometer (HyTES), Atmos. Meas. Tech., 9, 2393-2408, doi:10.5194/amt9-2393-2016, 2016.

IPCC: 2006 IPCC Guidelines for National Greenhouse Gas Inventories, Prepared by the National Greenhouse Gas Inventories Programme, edited by: Eggleston, H. S., Buendia, L., Miwa, K., Ngara, T., and Tanabe, K., IGES, Japan, 2006.

Kaminski, T., Rayner, P. J., Heimann, M., and Enting, I. G.: On aggregation errors in atmospheric transport inversions, J. Geophys. Res., 106, 4703, doi:10.1029/2000jd900581, 2001.

Karion, A., Sweeney, C., Pétron, G., Frost, G., Hardesty, R. M., Kofler, J., Miller, B. R., Newberger, T., Wolter, S., Banta, R., Brewer, A., Dlugokencky, E., Lang, P., Montzka, S. A., Schnell, R., Tans, P., Trainer, M., Zamora, R., and Conley, S.: Methane emissions estimate from airborne measurements over a western United States natural gas field, Geophys. Res. Lett., 40, 43934397, doi:10.1002/grl.50811, 2013.

Kiemle, C., Quatrevalet, M., Ehret, G., Amediek, A., Fix, A., and Wirth, M.: Sensitivity studies for a space-based methane lidar mission, Atmos. Meas. Tech., 4, 2195-2211, doi:10.5194/amt-42195-2011, 2011.

Kiemle, C., Kawa, S. R., Quatrevalet, M., and Browell, E. V.: Performance simulations for a spaceborne methane lidar mission, J. Geophys. Res.-Atmos., 119, 4365-4379, 2014.

Kirschke, S., Bousquet, P., Ciais, P., Saunois, M., Canadell, J. G., Dlugokencky, E. J., Bergamaschi, P., Bergmann, D., Blake, D. R., Bruhwiler, L., Cameron-Smith, P., Castaldi, S., Chevallier, F., Feng, L., Fraser, A., Heimann, M., Hodson, E. L., Houweling, S., Josse, B., Fraser, P. J., Krummel, P. B., Lamarque, J.F., Langenfelds, R. L., Le Quere, C., Naik, V., O’Doherty, S., Palmer, P. I., Pison, I., Plummer, D., Poulter, B., Prinn, R. G., Rigby, M., Ringeval, B., Santini, M., Schmidt, M., Shindell, D. T., Simpson, I. J., Spahni, R., Steele, L. P., Strode, S. A., Sudo, K., Szopa, S., van der Werf, G. R., Voulgarakis, A., van Weele, M., Weiss, R. F., Williams, J. E., and Zeng, G.: Three decades of global methane sources and sinks, Nat. Geosci., 6, 813-823, dio:10.1038/ngeo1955, 2013.

Kleipool, Q. L., Jongma, R. T., Gloudemans, A. M. S., Schrijver, H., Lichtenberg, G. F., van Hees, R. M., Maurellis, A. N., and Hoogeveen, R. W. M.: In-flight proton-induced radiation damage to SCIAMACHY's extended-wavelength InGaAs near-infrared detectors, Infrared Phys. Techn., 50, 30-37, 2007.

Kort, E. A., Frankenberg, C., Costigan, K. R., Lindenmaier, R., Dubey, M. K., and Wunch, D.: Four corners: The largest US methane anomaly viewed from space, Geophys. Res. Lett., 41, 6898-6903, 2014.

Krings, T., Gerilowski, K., Buchwitz, M., Reuter, M., Tretner, A., Erzinger, J., Heinze, D., Pflüger, U., Burrows, J. P., and Bovensmann, H.: MAMAP - a new spectrometer system for columnaveraged methane and carbon dioxide observations from aircraft: retrieval algorithm and first inversions for point source emission rates, Atmos. Meas. Tech., 4, 1735-1758, doi:10.5194/amt-41735-2011, 2011.

Krings, T., Gerilowski, K., Buchwitz, M., Hartmann, J., Sachs, T., Erzinger, J., Burrows, J. P., and Bovensmann, H.: Quantification of methane emission rates from coal mine ventilation shafts using airborne remote sensing data, Atmos. Meas. Tech., 6, 151-166, doi:10.5194/amt-6-151-2013, 2013. 
Kulawik, S., Wunch, D., O’Dell, C., Frankenberg, C., Reuter, M., Oda, T., Chevallier, F., Sherlock, V., Buchwitz, M., Osterman, G., Miller, C. E., Wennberg, P. O., Griffith, D., Morino, I., Dubey, M. K., Deutscher, N. M., Notholt, J., Hase, F., Warneke, T., Sussmann, R., Robinson, J., Strong, K., Schneider, M., De Mazière, M., Shiomi, K., Feist, D. G., Iraci, L. T., and Wolf, J.: Consistent evaluation of ACOS-GOSAT, BESD-SCIAMACHY, CarbonTracker, and MACC through comparisons to TCCON, Atmos. Meas. Tech., 9, 683-709, doi:10.5194/amt-9-683-2016, 2016.

Kuze, A., Suto, H., Shiomi, K., Kawakami, S., Tanaka, M., Ueda, Y., Deguchi, A., Yoshida, J., Yamamoto, Y., Kataoka, F., Taylor, T. E., and Buijs, H. L.: Update on GOSAT TANSO-FTS performance, operations, and data products after more than 6 years in space, Atmos. Meas. Tech., 9, 2445-2461, doi:10.5194/amt-92445-2016, 2016.

Lyon, D. R., Zavala-Araiza, D., Alvarez, R. A., Harriss, R., Palacios, V., Lan, X., Talbot, R., Lavoie, T., Shepson, P., Yacovitch, T. I., Herndon, S. C., Marchese, A. J., Zimmerle, D., Robinson, A. L., and Hamburg, S. P.: Constructing a spatially resolved methane emission inventory for the Barnett Shale region, Environ. Sci. Technol., 49, 8147-8157, 2015.

Maasakkers, J. D., Jacob, D. J., Sulprizio, M. P., Turner, A. J., Weitz, M., Wirth, T., Hight, C., DeFigueiredo, M., Desai, M., Schmeltz, R., Hockstad, L., Bloom, A. A., Bowman, K. W., Jeong, S., and Fischer, M. L.: Gridded national inventory of US methane emissions, Environ. Sci. Technol., doi:10.1021/acs.est.6b02878, in press, 2016.

Marais, E. A., Jacob, D. J., Wecht, K., Lerot, C., Zhang, L., Yu, K., Kurosu, T. P., Chance, K., and Sauvage, B.: Anthropogenic emissions in Nigeria and implications for ozone air quality: a view from space, Atmos. Environ., 99, 32-40, 2014.

Melton, J. R., Wania, R., Hodson, E. L., Poulter, B., Ringeval, B., Spahni, R., Bohn, T., Avis, C. A., Beerling, D. J., Chen, G., Eliseev, A. V., Denisov, S. N., Hopcroft, P. O., Lettenmaier, D. P., Riley, W. J., Singarayer, J. S., Subin, Z. M., Tian, H., Zürcher, S., Brovkin, V., van Bodegom, P. M., Kleinen, T., Yu, Z. C., and Kaplan, J. O.: Present state of global wetland extent and wetland methane modelling: conclusions from a model intercomparison project (WETCHIMP), Biogeosciences, 10, 753788, doi:10.5194/bg-10-753-2013, 2013.

Michalak, A. M., Bruhwiler, L., and Tans, P.: A geostatistical approach to surface flux estimation of atmospheric trace gases, $\mathrm{J}$. Geophys. Res., 109, D14109, doi:10.1029/2003JD004422, 2004.

Mikkela, C., Sundh, I., Svensson, B. H., and Nilsson, M.: Diurnal variation in methane emission in relation to the water table, soil temperature, climate and vegetation cover in a Swedish acid mire, Biogeochemistry, 28, 93-114, 1995.

Miller, S. M., Wofsy, S. C., Michalak, A. M., Kort, E. A., Andrews, A. E., Biraud, S. C., Dlugokencky, E. J., Eluskiewicz, J., Fisher, M. L., Janssens-Maenhout, G., Miller, B. R., Miller, J. B., Montzka, S. A., Nehrkorn, T., and Sweeney, C.: Anthropogenic emissions of methane in the US, P. Natl. Acad. Sci. USA, 110, 20018-20022, doi:10.1073/pnas.1314392110, 2013.

Miller, S. M., Michalak, A. M., and Levi, P. J.: Atmospheric inverse modeling with known physical bounds: an example from trace gas emissions, Geosci. Model Dev., 7, 303-315, doi:10.5194/gmd-7-303-2014, 2014.
Minschwaner, K. and Manney, G. L.: Derived methane in the stratosphere and lower mesosphere from Aura Microwave Limb Sounder measurements of nitrous oxide, water vapor, and carbon monoxide, J. Atmos. Chem., 71, 253-267, 2014.

Monteil, G., Houweling, S., Butz, A., Guerlet, S., Schepers, D., Hasekamp, O., Frankenberg, C., Scheepmaker, R., Aben, I., and Röckmann, T.: Comparison of $\mathrm{CH}_{4}$ inversions based on 15 months of GOSAT and SCIAMACHY observations, J. Geophys. Res.-Atmos., 118, 11807-11823, doi:10.1002/2013JD019760, 2013.

Myhre, G., Shindell, D., Bréon, F.-M., Collins, W., Fuglestvedt, J., Huang, J., Koch, D., Lamarque, J.-F., Lee, D., Mendoza, B., Nakajima, T., Robock, A., Stephens, G., Takemura, T., and Zhang, H.: Anthropogenic and Natural Radiative Forcing, in: Climate Change 2013: The Physical Science Basis. Contribution of Working Group I to the Fifth Assessment Report of the Intergovernmental Panel on Climate Change, edited by: Stocker, T. F., Qin, D., Plattner, G.-K., Tignor, M., Allen, S. K., Boschung, J., Nauels, A., Xia, Y., Bex, V., and Midgley, P. M., Cambridge University Press, Cambridge, United Kingdom and New York, NY, USA, 2013.

Ostler, A., Sussmann, R., Patra, P. K., Wennberg, P. O., Deutscher, N. M., Griffith, D. W. T., Blumenstock, T., Hase, F., Kivi, R., Warneke, T., Wang, Z., De Mazière, M., Robinson, J., and Ohyama, H.: The imprint of stratospheric transport on columnaveraged methane, Atmos. Chem. Phys. Discuss., 15, 20395 20447, doi:10.5194/acpd-15-20395-2015, 2015.

Pandey, S., Houweling, S., Krol, M., Aben, I., and Röckmann, T.: On the use of satellite-derived $\mathrm{CH}_{4}: \mathrm{CO}_{2}$ columns in a joint inversion of $\mathrm{CH}_{4}$ and $\mathrm{CO}_{2}$ fluxes, Atmos. Chem. Phys., 15, 86158629, doi:10.5194/acp-15-8615-2015, 2015.

Parker, R., Boesch, H., Cougan, A., Fraser, A., Feng, L., Palmer, P. I., Messerschmidt, J., Deutscher, N., Griffith, D. W. T., Notholt, J., Wennnberg, P. O., and Wunch, D.: Methane observations from the Greenhouse Gases Observing SATellite: Comparison to ground-based TCCON data and model calculations, Geophys. Res. Lett., 38, L15807, doi:10.1029/2011gl047871, 2011.

Parker, R. J., Boesch, H., Byckling, K., Webb, A. J., Palmer, P. I., Feng, L., Bergamaschi, P., Chevallier, F., Notholt, J., Deutscher, N., Warneke, T., Hase, F., Sussmann, R., Kawakami, S., Kivi, R., Griffith, D. W. T., and Velazco, V.: Assessing 5 years of GOSAT Proxy $\mathrm{XCH}_{4}$ data and associated uncertainties, Atmos. Meas. Tech., 8, 4785-4801, doi:10.5194/amt-8-4785-2015, 2015.

Patra, P. K., Houweling, S., Krol, M., Bousquet, P., Belikov, D., Bergmann, D., Bian, H., Cameron-Smith, P., Chipperfield, M. P., Corbin, K., Fortems-Cheiney, A., Fraser, A., Gloor, E., Hess, P., Ito, A., Kawa, S. R., Law, R. M., Loh, Z., Maksyutov, S., Meng, L., Palmer, P. I., Prinn, R. G., Rigby, M., Saito, R., and Wilson, C.: TransCom model simulations of $\mathrm{CH}_{4}$ and related species: linking transport, surface flux and chemical loss with $\mathrm{CH}_{4}$ variability in the troposphere and lower stratosphere, Atmos. Chem. Phys., 11, 12813-12837, doi:10.5194/acp-11-12813-2011, 2011.

Peischl, J., Karion, A., Sweeney, C., Kort, E. A., Smith, M. L., Brandt, A. R., Yeskoo, T., Aikin, K. C., Conley, S. A., Gvakharia, A., Trainer, M., Wolter, S., and Ryerson, T. B.: Quantifying atmospheric methane emissions from oil and natural gas production in the Bakken shale region of North Dakota, J. Geophys. Res., 121, 6101-6111, doi:10.1002/2015JD024631, 2016. 
Peters, W., Jacobson, A. R., Sweeney, C., Andrews, A. E., Conway, T. J., Masarie, K., Miller, J. B., Bruhwiler, L. M. P., Petron, G., Hirsch, A. I., Worthy, D. E. J., Van Der Werf, G. R., Randerson, J. T., Wennberg, P. O., Krol, M. C., and Tans, P. P.: An atmospheric perspective on North American carbon dioxide exchange: CarbonTracker, P. Natl. Acad. Sci. USA, 104, 1892518930, doi:10.1073/pnas.0708986104, 2007.

Polonsky, I. N., O’Brien, D. M., Kumer, J. B., O’Dell, C. W., and the geoCARB Team: Performance of a geostationary mission, geoCARB, to measure $\mathrm{CO}_{2}, \mathrm{CH}_{4}$ and $\mathrm{CO}$ column-averaged concentrations, Atmos. Meas. Tech., 7, 959-981, doi:10.5194/amt7-959-2014, 2014.

Prather, M. J.: Timescales in atmospheric chemistry: Theory, GWPs for $\mathrm{CH}_{4}$ and $\mathrm{CO}$, and runaway growth, Geophys. Res. Lett., 23, 2597-2600 1996.

Prather, M. J., Holmes, C. D., and Hsu, J.: Reactive greenhouse gas scenarios: Systematic exploration of uncertainties and the role of atmospheric chemistry, Geophys. Res. Lett., 39, L09803, doi:10.1029/2012GL051440, 2012.

Rayner, P. J., Utembe, S. R., and Crowell, S.: Constraining regional greenhouse gas emissions using geostationary concentration measurements: a theoretical study, Atmos. Meas. Tech., 7, 3285-3293, doi:10.5194/amt-7-3285-2014, 2014.

Remer, L. A., Mattoo, S., Levy, R. C., Heidinger, A., Pierce, R. B., and Chin, M.: Retrieving aerosol in a cloudy environment: aerosol product availability as a function of spatial resolution, Atmos. Meas. Tech., 5, 1823-1840, doi:10.5194/amt-5-1823-2012, 2012.

Roberts, D. A., Bradley, E. S., Cheung, R., Leifer, I., Dennison, P. E., and Margolis, J. S.: Mapping methane emissions from a marine geological seep source using imaging spectrometry, Remote Sens. Environ., 114, 592-606, 2010.

Rodgers, C. D.: Inverse Methods for Atmospheric Sounding, World Scientific Publishing Co., Singapore, 2000.

Saad, K. M., Wunch, D., Toon, G. C., Bernath, P., Boone, C., Connor, B., Deutscher, N. M., Griffith, D. W. T., Kivi, R., Notholt, J., Roehl, C., Schneider, M., Sherlock, V., and Wennberg, P. O.: Derivation of tropospheric methane from TCCON $\mathrm{CH}_{4}$ and $\mathrm{HF}$ total column observations, Atmos. Meas. Tech., 7, 2907-2918, doi:10.5194/amt-7-2907-2014, 2014.

Schepers, D., Guerlet, S., Butz, A., Landgraf, J., Frankenberg, C., Hasekamp, O., Blavier, J.-F., Deutscher, N. M., Griffith, D. W. T., Hase, F., Kyro, E., Morino, I., Sherlock, V., Sussmann, R., and Aben, I.: Methane retrievals from Greenhouse Gases Observing Satellite (GOSAT) shortwave infrared measurements: Performance comparison of proxy and physics retrieval algorithms, J. Geophys. Res., 117, D10307, doi:10.1029/2012JD017549, 2012.

Schneising, O., Burrows, J. P., Dickerson, R. R., Buchwitz, M., Reuter, M., and Bovensmann, H.: Remote sensing of fugitive methane emissions from oil and gas production in North American tight geologic formations, Earth's Future, 2, 548-558, 2014.

Shephard, M. W. and Cady-Pereira, K. E.: Cross-track Infrared Sounder (CrIS) satellite observations of tropospheric ammonia, Atmos. Meas. Tech., 8, 1323-1336, doi:10.5194/amt-8-13232015, 2015.

Shephard, M. W., Cady-Pereira, K. E., Luo, M., Henze, D. K., Pinder, R. W., Walker, J. T., Rinsland, C. P., Bash, J. O., Zhu, L., Payne, V. H., and Clarisse, L.: TES ammonia retrieval strategy and global observations of the spatial and seasonal vari- ability of ammonia, Atmos. Chem. Phys., 11, 10743-10763, doi:10.5194/acp-11-10743-2011, 2011.

Spahni, R., Wania, R., Neef, L., van Weele, M., Pison, I., Bousquet, P., Frankenberg, C., Foster, P. N., Joos, F., Prentice, I. C., and van Velthoven, P.: Constraining global methane emissions and uptake by ecosystems, Biogeosciences, 8, 1643-1665, doi:10.5194/bg8-1643-2011, 2011.

Streets, D., Canty, T., Carmichael, G., de Foy, B., Dickerson, R., Duncan, B., Edwards, D., Haynes, J., Henze, D., Houyoux, M., Jacob, D., Krotkov, N., Lamsal, L., Liu, Y., Lu, Z., Martin, R., Pfister, G., Pinder, R., Salawitch, R., and Wecht, K.: Emissions estimation from satellite retrievals: A review of current capability, Atmos. Environ., 77, 1011-1042, 2013.

Thompson, D. R., Leifer, I., Bovensmann, H., Eastwood, M., Fladeland, M., Frankenberg, C., Gerilowski, K., Green, R. O., Kratwurst, S., Krings, T., Luna, B., and Thorpe, A. K.: Real-time remote detection and measurement for airborne imaging spectroscopy: a case study with methane, Atmos. Meas. Tech., 8, 4383-4397, doi:10.5194/amt-8-4383-2015, 2015.

Thorpe, A. K., Frankenberg, C., Aubrey, A. D., Roberts, D. A., Nottrott, A. A., Rahn, T. A., Sauer, J. A., Dubey, M. K., Costigan, K. R., Arata, C., Steffke, A. M., Hills, S., Haselwimmer, C., Charlesworth, D., Funk, C. C., Green, R. O., Lundeen, S. R., Boardman, J. W., Eastwood, M. L., Sarture, C. M., Nolte, S. H., Mccubbin, I. B., Thompson, D. R., and McFadden, J. P.: Mapping methane concentrations from a controlled release experiment using the next generation airborne visible/infrared imaging spectrometer (AVIRIS-NG), Remote Sens. Environ., 179, 104115, 2016.

Tratt, D. M., Buckland, K. N., Hall, J. L., Johnson, P. D., Keim, E. R., Leifer, I., Westberg, K., and Young, S. J.: Airborne visualization and quantification of discrete methane sources in the environment, Remote Sens. Environ., 154, 74-88, 2014.

Turner, A. J. and Jacob, D. J.: Balancing aggregation and smoothing errors in inverse models, Atmos. Chem. Phys., 15, 7039-7048, doi:10.5194/acp-15-7039-2015, 2015.

Turner, A. J., Jacob, D. J., Wecht, K. J., Maasakkers, J. D., Lundgren, E., Andrews, A. E., Biraud, S. C., Boesch, H., Bowman, K. W., Deutscher, N. M., Dubey, M. K., Griffith, D. W. T., Hase, F., Kuze, A., Notholt, J., Ohyama, H., Parker, R., Payne, V. H., Sussmann, R., Sweeney, C., Velazco, V. A., Warneke, T., Wennberg, P. O., and Wunch, D.: Estimating global and North American methane emissions with high spatial resolution using GOSAT satellite data, Atmos. Chem. Phys., 15, 7049-7069, doi:10.5194/acp-15-7049-2015, 2015.

Turner, A. J., Jacob, D. J., Benmergui, J., Wofsy, S. C., Maasakkers, J. D., Butz, A., Hasekamp, O., Biraud, S. C., and Duglokencky, E.: A large increase in US methane emissions over the past decade inferred from satellite data, Geophys. Res. Lett., 43, 2218-2224, doi:10.1002/2016GL067987, 2016.

US EPA: Inventory of U.S. greenhouse gas emissions and sinks: 1990-2012, available at: https://www3.epa.gov/climatechange/ ghgemissions/usinventoryreport.html (last access: 16 November 2016), 2016.

Van Damme, M., Wichink Kruit, R. J., Schaap, M., Clarisse, L., Clerbaux, C., Coheur, P.-F., Dammers, E., Dolman, A. J., and Erisman, J. W.: Evaluating 4 years of atmospheric ammonia $\left(\mathrm{NH}_{3}\right)$ over Europe using IASI satellite observations and 
LOTOS-EUROS model results, J. Geophys. Res., 119, 95499566, 2014

Veefkind, J. P., Aben, I., McMullan, K., Forster, H., de Vries, J., Otter, G., Claas, J., Eskes, H. J., de Haan, J. F., Kleipool, Q., van Weele, M., Hasekamp, O., Hoogeveen, R., Landgraf, J., Snel, R., Tol, P., Ingmann, P., Voors, R., Kruizinga, B., Vink, R., Visser, H., and Levelt, P. F.: TROPOMI on the ESA Sentinel-5 Precursor: A GMES mission for global observations of the atmospheric composition for climate, air quality and ozone layer applications, Remote Sens. Environ., 120, 70-83, 2012.

von Clarmann, T., Höpfner, M., Kellmann, S., Linden, A., Chauhan, S., Funke, B., Grabowski, U., Glatthor, N., Kiefer, M., Schieferdecker, T., Stiller, G. P., and Versick, S.: Retrieval of temperature, $\mathrm{H}_{2} \mathrm{O}, \mathrm{O}_{3}, \mathrm{HNO}_{3}, \mathrm{CH}_{4}, \mathrm{~N}_{2} \mathrm{O}, \mathrm{ClONO}_{2}$ and $\mathrm{ClO}$ from MIPAS reduced resolution nominal mode limb emission measurements, Atmos. Meas. Tech., 2, 159-175, doi:10.5194/amt-2-159-2009, 2009.

Voulgarakis, A., Naik, V., Lamarque, J.-F., Shindell, D. T., Young, P. J., Prather, M. J., Wild, O., Field, R. D., Bergmann, D., CameronSmith, P., Cionni, I., Collins, W. J., Dalsøren, S. B., Doherty, R. M., Eyring, V., Faluvegi, G., Folberth, G. A., Horowitz, L. W., Josse, B., MacKenzie, I. A., Nagashima, T., Plummer, D. A., Righi, M., Rumbold, S. T., Stevenson, D. S., Strode, S. A., Sudo, K., Szopa, S., and Zeng, G.: Analysis of present day and future $\mathrm{OH}$ and methane lifetime in the ACCMIP simulations, Atmos. Chem. Phys., 13, 2563-2587, doi:10.5194/acp-13-25632013, 2013.

Wang, H., Jacob, D. J., Kopacz, M., Jones, D. B. A., Suntharalingam, P., Fisher, J. A., Nassar, R., Pawson, S., and Nielsen, J. E.: Error correlation between $\mathrm{CO}_{2}$ and $\mathrm{CO}$ as constraint for $\mathrm{CO}_{2}$ flux inversions using satellite data, Atmos. Chem. Phys., 9, 7313-7323, doi:10.5194/acp-9-7313-2009, 2009.

Wang, Y.-P. and Bentley, S. T.: Development of a spatially explicit inventory of methane emissions from Australia and its verification using atmospheric concentration data, Atmos. Environ., 36, 4985-4975, 2002.

Wecht, K. J., Jacob, D. J., Wofsy, S. C., Kort, E. A., Worden, J. R., Kulawik, S. S., Henze, D. K., Kopacz, M., and Payne, V. H.: Validation of TES methane with HIPPO aircraft observations: implications for inverse modeling of methane sources, Atmos. Chem. Phys., 12, 1823-1832, doi:10.5194/acp-12-1823-2012, 2012.

Wecht, K. J., Jacob, D. J., Frankenberg, C., Jiang, Z., and Blake, D. R.: Mapping of North America methane emissions with high spatial resolution by inversion of SCIAMACHY satellite data, J. Geophys. Res., 119, 7741-7756, doi:10.1002/2014JD021551, 2014a.

Wecht, K. J., Jacob, D. J., Sulprizio, M. P., Santoni, G. W., Wofsy, S. C., Parker, R., Bösch, H., and Worden, J.: Spatially resolving methane emissions in California: constraints from the CalNex aircraft campaign and from present (GOSAT, TES) and future (TROPOMI, geostationary) satellite observations, Atmos. Chem. Phys., 14, 8173-8184, doi:10.5194/acp-14-8173-2014, 2014b.

Wennberg, P. O., Mui, W., Wunch, D., Kort, E. A., Blake, D. R., Atlas, E. L., Santoni, G. W., Wofsy, S. C., Diskin, G. S., Jeong, S., and Fischer, M. L.: On the sources of methane to the Los Angeles atmosphere, Environ. Sci. Technol., 46, 9282-9289, 2012.

Wofsy, S. C.: HIAPER Pole-to-Pole Observations (HIPPO): finegrained, global-scale measurements of climatically important at- mospheric gases and aerosols, Philos. T. R. Soc. A, 369, 20732086, 2011.

Wood, J. D., Gordon, R. J., and Wagner-Riddle, C.: Biases in discrete $\mathrm{CH}_{4}$ and $\mathrm{N}_{2} \mathrm{O}$ sampling protocols associated with temporal variation of gas fluxes from manure storage systems, Agr. Forest Meteorol., 171-172, 295-305, 2013.

Worden, H. M., Deeter, M. N., Edwards, D. P., Gille, J. C., and Drummond, J. R.: Observations of near-surface carbon monoxide from space using MOPITT multispectral retrievals, J. Geophys. Res., 115, D18314, doi:10.1029/2010JD014242, 2010.

Worden, J., Kulawik, S., Frankenberg, C., Payne, V., Bowman, K., Cady-Peirara, K., Wecht, K., Lee, J.-E., and Noone, D.: Profiles of $\mathrm{CH}_{4}, \mathrm{HDO}, \mathrm{H}_{2} \mathrm{O}$, and $\mathrm{N}_{2} \mathrm{O}$ with improved lower tropospheric vertical resolution from Aura TES radiances, Atmos. Meas. Tech., 5, 397-411, doi:10.5194/amt-5-397-2012, 2012.

Worden, J., Wecht, K., Frankenberg, C., Alvarado, M., Bowman, K., Kort, E., Kulawik, S., Lee, M., Payne, V., and Worden, H.: $\mathrm{CH}_{4}$ and $\mathrm{CO}$ distributions over tropical fires during October 2006 as observed by the Aura TES satellite instrument and modeled by GEOS-Chem, Atmos. Chem. Phys., 13, 3679-3692, doi:10.5194/acp-13-3679-2013, 2013.

Worden, J. R., Turner, A. J., Bloom, A., Kulawik, S. S., Liu, J., Lee, M., Weidner, R., Bowman, K., Frankenberg, C., Parker, R., and Payne, V. H.: Quantifying lower tropospheric methane concentrations using GOSAT near-IR and TES thermal IR measurements, Atmos. Meas. Tech., 8, 3433-3445, doi:10.5194/amt-83433-2015, 2015

Wunch, D., Toon, G. C., Blavier, J.-F. L., Waschenfelder, R. A., Notholt, J., Connor, B. J., Griffith, D. W. T., Sherlock, V., and Wennberg, P. O.: The Total Carbon Column Observing Network, Philos. T. R. Soc. A, 369, 2087-2112, 2011.

Xi, X., Natraj, V., Shia, R. L., Luo, M., Zhang, Q., Newman, S., Sander, S. P., and Yung, Y. L.: Simulated retrievals for the remote sensing of $\mathrm{CO}_{2}, \mathrm{CH}_{4}, \mathrm{CO}$, and $\mathrm{H}_{2} \mathrm{O}$ from geostationary orbit, Atmos. Meas. Tech., 8, 4817-4830, doi:10.5194/amt-84817-2015, 2015.

Xiao, Y, Jacob, D. J., Wang, J., Logan, J. A., Palmer, P. I., Suntharalingam, P., Yantosca, R. M., Sachse, G. W., Blake, D. R. and Streets, D. G.: Constraints on Asian and European sources of methane from $\mathrm{CH}_{4}-\mathrm{C}_{2} \mathrm{H}_{6}$-CO correlations in Asian outflow, $\mathrm{J}$. Geophys. Res., 109, D15S16, doi:10.1029/2003JD004475, 2004.

Xiong, X., Barnet, C., Maddy, E., Sweeney, C., Liu, X., Zhou, L., and Goldberg, M.: Characterization and validation of methane products from the Atmospheric Infrared Sounder (AIRS), J. Geophys. Res., 113, G00A01, doi:10.1029/2007JG000500, 2008.

Xiong, X., Barnet, C., Maddy, E. S., Gambacorta, A., King, T. S., and Wofsy, S. C.: Mid-upper tropospheric methane retrieval from IASI and its validation, Atmos. Meas. Tech., 6, 2255-2265, doi:10.5194/amt-6-2255-2013, 2013.

Zavala-Araiza, D., Lyon, D., Alvarez, R. A., Palacios, V., Harriss, R., Lan, X., Talbot, R., and Hamburg, S. P.: Toward a functional definition of methane super-emitters: application to natural gas production sites, Environ. Sci. Technol., 49, 8167-8174, 2015.

Zhang, L., Jacob, D. J., Liu, X., Logan, J. A., Chance, K., Eldering, A., and Bojkov, B. R.: Intercomparison methods for satellite measurements of atmospheric composition: application to tropospheric ozone from TES and OMI, Atmos. Chem. Phys., 10, 4725-4739, doi:10.5194/acp-10-4725-2010, 2010. 
Zhao, C., Andrews, A. E., Bianco, L., Eluszkiewicz, J., Hirsch, A., MacDonald, C., Nehrkorn, T., and Fischer, M. L.: Atmospheric inverse estimates of methane emissions from Central California, J. Geophys. Res., 114, D16302, doi:10.1029/2008JD011671, 2009.

Zhu, L., Henze, D. K., Cady-Pereira, K. E., Shephard, M. W., Luo, M., Pinder, R. W., Bash, J. O., and Jeong, G.-R.: Constraining U.S. ammonia emissions using TES remote sensing observations and the GEOS-Chem adjoint model, J. Geophys. Res., 118, 3355-3368, 2013.
Zoogman, P., Jacob, D. J., Chance, K., Liu, X., Lin, M., Fiore, A., and Travis, K.: Monitoring high-ozone events in the US Intermountain West using TEMPO geostationary satellite observations, Atmos. Chem. Phys., 14, 6261-6271, doi:10.5194/acp-146261-2014, 2014. 